\begin{abstract}
Title of Dissertation:

SELF-DIRECTED LEARNING IN THE

WORKPLACE

Amy Buhl Conn, Doctor of Philosophy, 2000

Dissertation directed by: Professor and Dean Irwin L. Goldstein

College of Behavioral and Social Sciences
\end{abstract}

Rapid changes in workplace (e.g., technology, organizational structure) increase the complexity of work which, in turn, increases the demand for continual learning. Current training efforts, in which organizations sponsor employee training in some form, are insufficient in meeting this demand for training. As a result, organizations have embraced the principles of self-directed learning (SDL) and encouraged employees to assume some responsibility for their own learning. Yet, the effectiveness of SDL in the workplace has received little empirical attention. Previous research has demonstrated that individuals high in SDL readiness (i.e., individuals who prefer guiding and directing their own learning as opposed to a teacher-centered format) received higher overall performance ratings. However, researchers have not examined the effect of actual SDL experience on either overall performance or performance in the specific area related to those SDL 
experiences. While it has been maintained that SDL is an effective form of workplace training to improve job performance, this assumption has not been tested. The goal of the present research was to test this assertion by evaluating a SDL program (i.e., an on-line listening skills course) currently in place. Measures of individuals' SDL readiness, work locus of control, cognitive ability, SDL activities, learning acquisition, and job performance were examined before and after engaging in the SDL program. A control group was secured for comparison, thereby providing a better test of the propositions. Results supported many of the proposed relationships. In particular, SDL readiness and work locus of control predicted membership in the target SDL course and the extent to which participants engaged in the course. Participation in the listening skills course and the extent to which they engaged in the course predicted greater learnings, which in turn predicted improved listening skills performance three months after the completion of the course. Implications of the results as it relates to past research, limitations of the study, and directions for future research are discussed. 


\title{
SELF-DIRECTED LEARNING IN THE WORKPLACE
}

by

\author{
Amy Buhl Conn
}

Dissertation submitted to the Faculty of the Graduate School of the University of Maryland, College Park in partial fulfillment

of the requirements for the degree of

Doctor of Philosophy

2000

Advisory Committee:

Professor and Dean Irwin L. Goldstein, Chair

Professor Paul J. Hanges

Professor Katherine J. Klein

Professor Benjamin Schneider

Professor Susan M. Taylor 


\section{DEDICATION}

In memory of Steve (November 1997 to October 2000). 


\section{ACKNOWLEDGEMENTS}

Many thanks to my committee, Irv Goldstein, Paul Hanges, Katherine Klein, Ben Schneider, and Susan Taylor, for their contributions and continued support throughout. Thanks to Michelle Paul for her peer reviews and adding structure and deadlines to the jello-like process. And last but not least, thanks to my typist and husband, Adam Conn. 


\section{TABLE OF CONTENTS}

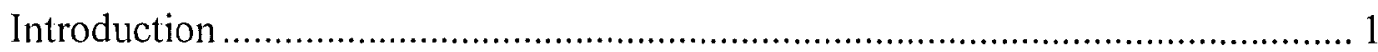

Overview: The Need for SDL in the Workplace............................................. 3

Literature Review: Implications for SDL in the Workplace........................... 11

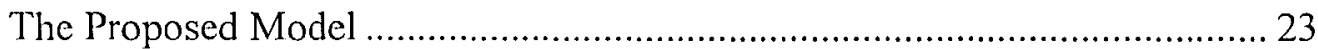

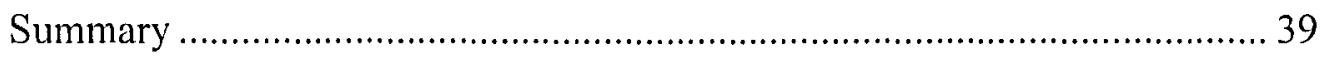

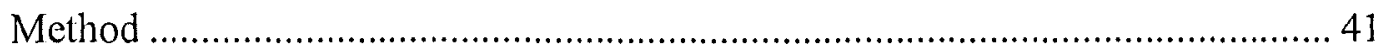

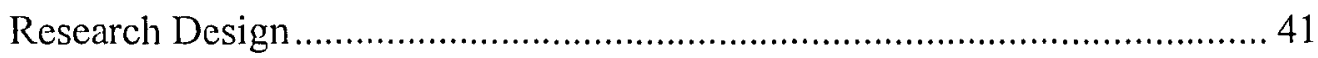

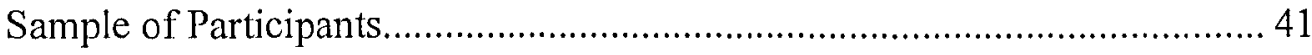

Listening Skills Course Description .............................................................. 43

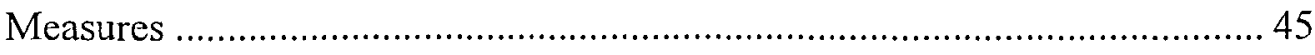

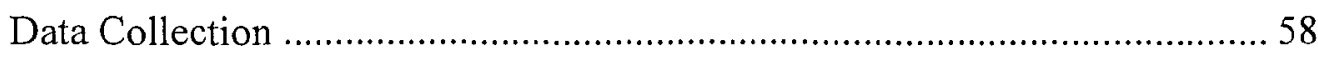

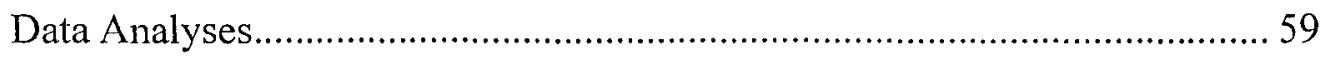

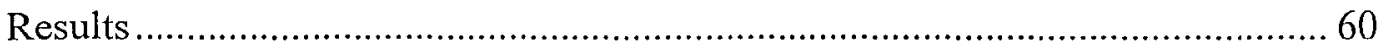

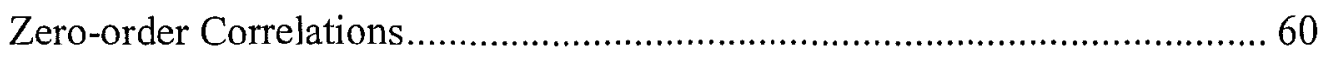

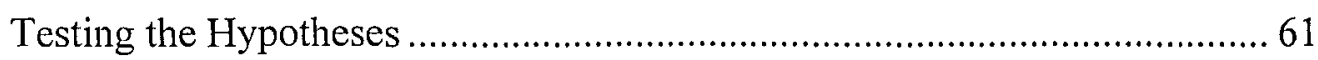

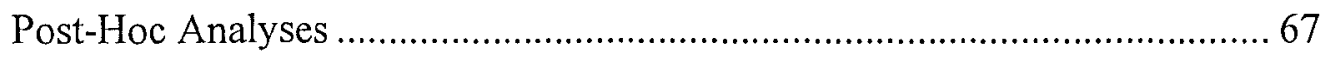

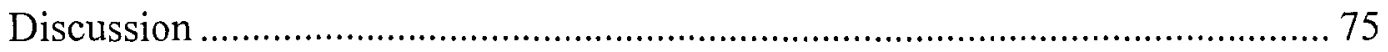

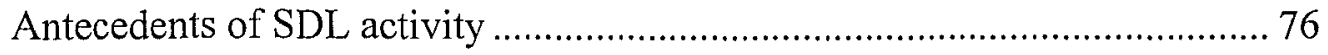

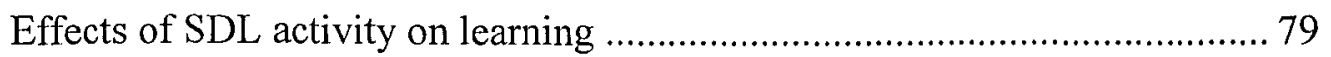




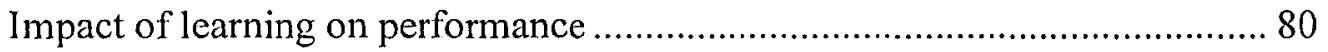

SDL as a mediator of the SDL readiness-performance relationship ............... 81

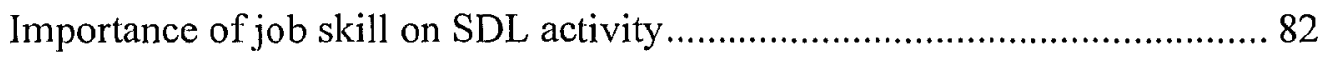

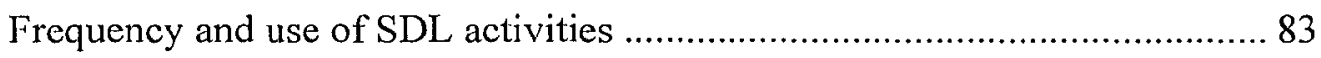

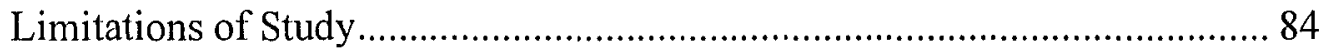

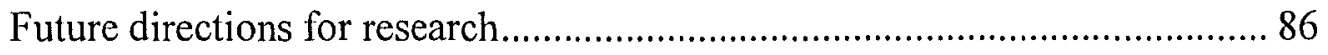

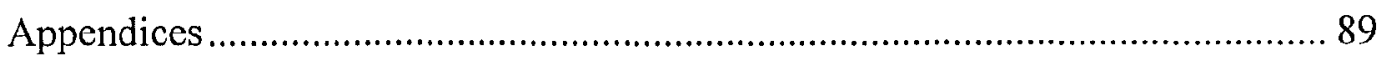

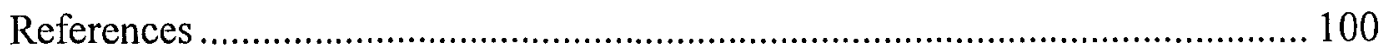


Self-Directed Learning in the Workplace

Rapid technological advances and other changes continuously alter the nature and complexity of work (Cascio, 1995; Goldstein, 1993; Howard, 1995). These changes require substantial, continuous training to ensure a productive workforce and organizational effectiveness. Organizations shoulder the heavy burden to find or create workers with the necessary skills. The scarcity of wellskilled workers (Cappelli et al., 1997) requires organizations to train and continually retrain their employees. But organizations' heavy reliance on traditional training approaches ( $70 \%$ of training efforts are classroom-oriented training, ASTD Benchmarking Forum, 1997), are no longer adequate. These current training efforts cannot reach enough people: less than half of the workforce receives formal training (Campbell, 1991).

Alternative training methods such as self-directed learning (SDL) allow employees to assume responsibility for their own training and serve as a means to meet the growing demand for training. Self-directed learning (SDL) takes place outside of a formal classroom -- individuals assume responsibility for their own learning and seek out their own learning experiences. The individual serves as a self-trainer by assessing his or her own needs and acquiring the desired skills without the aid of a trainer or instructor. In a work world where continuous learning is a necessity (Cascio, 1995; Oddi, 1987; Zemke, 1998), SDL as a training 
approach may serve as a great benefit to organizations and individuals: it allows for a broad range of individuals to address their training needs individually. As a result, organizations are readily implementing SDL programs in an effort to maintain a well-skilled workforce.

However, research is still needed in this area. The concept of SDL as a workplace training approach is still in its infancy as is our knowledge of its effectiveness. While some adult education researchers have begun to examine SDL in organizations, many questions remain unanswered. Are SDL programs effective (i.e., do employees learn the material as intended)? Does learning acquisition from SDL programs transfer back to the job thereby improving job performance? Does an individual's preference for SDL influence his or her decision to engage in SDL activities? It is generally held that these programs improve performance, either overall performance or in a particular skill area, yet there is little empirical evidence to back this claim.

The proposed study aimed to evaluate the effectiveness of an intact SDL program and, in the process, illustrate the links between SDL readiness, involvement and learning in a SDL activity, and performance. This study evaluated the effectiveness of a SDL program by not only examining learning acquisition but the impact of such learning on job performance. Also, this research further bridged the gap between two inherently related fields -- adult education and organizational 
training research -- by studying SDL as a training method. And finally, this research sought to gain a richer understanding of the relationship between SDL readiness and performance by examining the process in which SDL readiness may result in better job performance (i.e., through SDL activity and learning).

In the following sections, I first provide some background regarding changes taking place within the workplace that have heightened the demand and urgency for training. I then describe how SDL may serve as a useful training approach for organizations. I next review existing literature on SDL and highlight the limited research on SDL in organizational settings. I then present my model and hypotheses.

Overview: The Need for Self-Directed Learning in the Workplace Rapid changes in the workplace driven by technology have produced an increasingly complex work environment over the past couple decades. Changes in technology have increased the amount and type of skills required by the average worker, creating a heavy demand for training. The impact of technological advancements on the workplace and employees' skills is described in this section. From this material, it is obvious that current training efforts cannot meet the demand for training but through alternative, supplemental training strategies, organizations may be better able to maintain an upskilled workforce. Self-directed learning is one such alternative training approach. 
As technology continues to evolve rapidly, the way work is done changes (Craiger, 1997) and workers experience an increased rate of skill obsolescence (Kaufman, 1995), increasing the demand for training. Employees undertake frequent retraining to keep their skills current because "if work processes are being reorganized around greater efficiencies afforded by computers, then anyone not reskilling will move down and out, not up and in" (Olson, 1987, p. 194; as cited in LeBlanc, 1994). For example, many software packages experienced a dramatic transition in functionality and methodology as industry transitioned from DOSbased programs to Windows-driven programs. This transition from clunky textand keyboard- driven commands to "friendlier and easier-to-use" mouse-driven menus had unintended consequences. WordPerfect, notably, transitioned both late and, some argue, poorly. Those used to the final DOS-based program (version 5.1) had a difficult time transitioning to the first Windows versions (5.2 and 6.0) largely because users needed to be completely retrained. Users had to learn a new menu system and relearn the drastically changed "keyboard shortcuts." These users have also had to pay a larger penalty as WordPerfect has lost market share and identity through a series of acquisitions (first by Novell, then by Corel) and product delays. More work sites have transitioned away from WordPerfect to Microsoft Word, requiring more training and retraining. This phenomena is not limited to general programs such as a word processor -- it appears in almost any change of 
technology, small or large. As our workforce becomes increasingly technologically complex, organizations are faced with the burden of retraining a large portion of their workforce.

Unfortunately, current training efforts cannot satisfy such a tireless demand for continuous learning. Even though organizations invest billions of dollars into training, not enough individuals receive training (Carnevale, 1995; Cascio, 1995). There are simply too many people in need of training. Further compounding the problem, technology changes so quickly that a training program is often outdated by the time it has been developed (Tannenbaum $\&$ Yukl, 1992). Simply put: "Too many people need too much training, and too much of it is individually idiosyncratic. Companies' needs for learning today are too great and too immediate to be hamstrung by stodgy program development, rigid scheduling, and analretentive gatekeeping" (Zemke, 1998, p. 60).

The focus here on technology is not meant to deny that other current changes at work also impact the need for training (cf. Conn, 1998). For example, continual downsizing has resulted in fewer employees left to do more work for less pay (Hall \& Mirvis, 1995). The work is often new to the surviving employees, requiring training to learn their new roles (Kaufman, 1995). Similarly, changes in organizational structure (e.g., flatter hierarchy) and employee empowerment alter employees' roles providing them with greater responsibilities and, hence, the need 
to learn a broad range of new skills such as problem solving, decision-making, customer service, and general business and economic skills (Lawler, 1993). An increase in the use of teamwork requires employees to work together, heightening the need for training on interpersonal skills and team building. As noted by Hopkins, Sterkel-Powell, and Hopkins (1994), these skills are sorely lacking in today's workforce. Also, as organizations evolve into "leaner and meaner" entities, their use of the contingent workforce has risen, creating the need for continuous training (Feldman, 1995). These changes further increase the demand for training as organizations are pressed to find ways to meet this ever-growing demand.

Organizations have therefore encouraged, developed, and implemented alternative training methods (such as self-directed learning) that enable the individual worker to shoulder some of the responsibility. Ironically, the same technological advances that have increased the burden for training (i.e., computers and the Internet) also provide the means for self-directed learning. For example, General Electric has put their sales training on-line. Thomson Financial offers a wide variety of interactive on-line training including management skills development (e.g., Leadership 2000), general skills development (e.g., time management), and technical training (e.g., Microsoft Certified Engineer course for system administrators). By encouraging employees to be more self-directed in their learning, organizations provide everyone with the ability to engage in their own 
development. As stated by Oddi, "the ability to be a self-directed learner is a requirement for all adults in a rapidly-changing, technologically complex society" (1987, p. 21). Encouraging individuals to engage in self-directed learning may be a key factor in maintaining an adequately skilled, adaptable workforce in the face of continuous change. But first, we must develop an understanding of self-directed learning before we can leverage it as a useful training mechanism.

Numerous terms have been associated with self-directed learning (SDL) including: autonomous learning, independent learning, self-planned learning, selfinstruction, self-teaching, self-study, self-education, and discovery learning (Guglielmino, 1977, pp. 6-7). While each of these carry slightly different connotations, all of these terms highlight autonomy, initiative, and self-paced learning. Typically, SDL is defined as learning that takes place independent of formal, classroom instruction (Campbell, 1991) where learning is controlled by the learner, as opposed to a teacher or trainer (Spear \& Mocker, 1984). SDL as a training mechanism entails providing the learner with some control over the training process, including developing his or her learning goals, selecting the materials to be used, and/or conducting a self-evaluation (DeJoy \& DeJoy, 1987; Hatcher, 1997).

Individuals learn through SDL activity much in the same manner they do in a formal training program. They proceed through a multi-step process, similar to 
the training process discussed by Goldstein (1993), that includes developing learning goals (based on some form of needs analysis), choosing the appropriate learning material and resources, following a learning strategy, and evaluating learning. However, under the SDL approach, the trainee takes responsibility for the process, not the trainer as is typically the case in training. Specifically, an individual engages in a needs assessment (i.e., diagnoses his or her learning needs) and sets learning goals. Next, an individual develops a learning strategy and selects the appropriate learning materials. After completing the planned study, the individual then evaluates his or her own learning to determine if the learning goals were met. SDL programs may not meet all these criteria. A self-directed program may entail anywhere from one to all of these steps. For example, the needs analysis may be performed by the organization through an assessment or a $360^{\circ}$ feedback tool. The employee would then select a self-study program targeted at the necessary skills (e.g., an on-line course designed to improve time management skills). Another variation would be group-based learning. SDL need not be exclusively independent: SDL can occur through the use of leaderless groups (Hatcher, 1997).

One type of SDL training program is the on-line self-study course. This type of program is designed such that individuals can connect through their intranet, extranet, or Internet to learning material made available. Individuals can 
then proceed through the course at their own pace. The self-study course can be designed to conduct a pre-assessment to serve as a form of training needs analysis, test the individuals on the learned material at various points during the course (e.g., unit tests or small assignments) or at the end of the course (e.g., a final comprehensive exam) to identify areas for review. Based on the individual's performance, computer-generated recommendations for further study could then be presented to the learner.

This description represents only one possible form of the on-line self-study training program. These types of programs could vary in many ways. For example, learning evaluation may not be a component; the program could just present the material leaving it in the hands of the individuals to evaluate their own learning. The on-line material could be used in conjunction with workshops or group discussions. The program may require individuals to work on the material for set times as opposed to permitting the individual to set his or her own pace. Or, the order in which individuals are presented with the learning material may be at the discretion of the individual (e.g., they could skip a section if redundant with their current knowledge or skills).

Of course, on-line self-study represents only one type of SDL training program. Employees seeking to develop their knowledge and skills have a host of options. Individuals may use the library, books, or CD-ROMs as resources to 
engage in their self-study; or they may choose to gain insight from people such as mentors, peers, experts, or by attending professional conferences. Learning activities could include anything from taking a course (e.g., correspondence courses, on-line self-study, other distance learning) to learning through experience (e.g., joining a task force, job rotation).

As discussed by Abbott and Dahmus (1992), SDL has several advantages over formal instruction. First, the learning content can be matched to individuals' needs. Second, there is greater flexibility in timing (i.e., learners can work at their own pace and on their own schedule) and the availability of learning resources. Third, SDL can be quite responsive to individuals' changing needs for information and skills. And fourth, SDL can be very cost effective for organizations. Employees shouldering the responsibility for their own training greatly reduces the time and financial costs organizations invest in training and program development. SDL training programs may be even more cost-effective when consistent training across multiple sites is needed because fewer qualified instructors are required (Piskurich, 1991).

However, before organizations may reap the benefits of SDL-based training, more research involving work organizations is needed. The knowledge we have regarding SDL stems primarily from the adult education literature; and while it has been suggested that the principles of SDL may be applied to the work setting 
(Gugliclmino, Guglielmino, \& Long, 1987), such assertions remain largely untested. Most research has focused on academic settings, particularly graduate school programs. As a result, very little information on the effectiveness of SDL in the workplace is available.

In the next section, I will review what has been learned in the adult education field regarding SDL, highlighting three streams of research and the implications for SDL in the workplace.

\author{
A Review of the Adult Education Literature \\ and the Implications for SDL in the Workplace
}

While research on SDL in work organizations is still in its infancy, adult education researchers have studied SDL for over two decades. From their findings, we can draw certain conclusions regarding the appropriateness and use of SDL in the workplace. In this section, I review the research from the adult education literature and discuss the implications of such findings for work-directed SDL. I then concentrate on the handful of SDL studies that have been conducted in organizational settings and discuss some remaining gaps that require further study. As reviewed by Brockett (1985a) and Fitzgibbons (1990), SDL research has followed three streams. The first stream consists of survey research that has focused on "the frequency and nature of learning projects undertaken by adults" (Brockett, 1985a, p. 16). The second stream deals with primarily qualitative 
research concerned with understanding the meaning of SDL. And the third stream consists of a growing body of research surrounding the Self-Directed Learning Readiness Scale (SDLRS), an instrument that diagnoses an individual's readiness (or preference) to engage in SDL.

The Frequency and Nature of Learning Projects

The early work of Tough (1971) started a series of studies that have examined the extent to which adults were engaged in adult learning projects and the nature of these projects. "A learning project is a highly deliberate effort to gain and retain certain definite knowledge and/or skills, or to change in some other way....Any method can be included -- reading, listening, observing, attending class, reflecting, practicing, getting answers to questions" provided the learning sessions add up to 7 hours or more (Tough, 1978, p. 250). As explained by Tough (1978, p. 250), the learning project may be self-planned, classroom learning, guided by a friend, or programmed instruction. The goal of the learning project may vary, for example, report writing, building something, raising a child, or sewing a dress. Adults may set out to learning something for sake of their jobs or out of curiosity, interest or enjoyment.

Research has found that a large majority of adults engage in learning projects, both job-related and recreational, and that these adults prefer SDL as opposed to classroom- or instructor-based learning. Specifically, Tough (1971) 
interviewed 200 Canadian adults and found that approximately $90 \%$ of adults are engaged in at least one learning project each year. In a subsequent study, Penland (1977) found that nearly $80 \%$ of adults consider themselves to be continuous learners and prefer to conduct their learning at home. He found adults used their learning in various areas of life, including (rank-ordered): "personal development, home and family, hobbies and recreation, general education, job, religion, voluntary activity, public affairs, and agriculture/technology" (p. 40).

As reviewed by Tough (1978), a wide body of evidence supports the notion that adults are actively engaged in learning projects for both selffulfillment/recreational and job purposes. Specifically, Hiemstra's (1976) study of 256 adults (age 55 and older) found that more than half of adult learning projects were for self-fulfillment with fewer projects devoted to learning job skills. Johnson, Levine, and Rosenthal (1977) found that unemployed adults devote time to learn coping skills, job-searching skills, and preparing for a job. A study of professional men (McCatty, 1975) concluded that $55 \%$ of their learning projects were job-related (e.g., keeping up with literature). Similarly, $85 \%$ of college and university administrators' learning projects were job-related (Benson, 1975). Ministers devoted $62 \%$ of their time to their vocation (Allerton, 1975). And pharmacists spent $30 \%$ of their learning projects on vocational subject matter, with 
the remaining projects focused on recreation, home and family, and public affairs (Johns, 1974).

Implications. These studies support Knowles' (1975) assertion that the majority of adults actively engage in learning and prefer to learn in a self-directed manner. As documented in the research above, working adults are already engaging in work-directed SDL activities. Therefore, organizations may be able to successfully promote SDL programs in the workplace. Based on the research cited above, individuals are already learning job-related skills on their own and may prefer to take SDL programs as opposed to traditional instructor-based training programs to learn work-related skills.

\section{The Meaning of Self-Directed Learning}

Through the use of qualitative methods (e.g., case studies, content analysis, interviews), researchers have gained a richer understanding of SDL (Brockett, 1985a). These studies have focused on either the self-directed learner (e.g., qualities of the individual) or the self-directed learning process (e.g., types of learning materials or resources used). Learner-centered research has uncovered various qualities that self-directed learners share. For example, Gibbons et al. (1980) performed a content analysis on the biographies of prominent individuals lacking in formal education and found that these individuals shared several traits including: perseverance, curiosity, ambition, industriousness, self-discipline, 
creativity, non-conformity, and self-motivation. Similarly, Houle (1961) in 22 adult case studies found three types of learners: "goal-oriented learners, who use learning to gain specific objectives; activity-oriented learners, who use learning primarily for an activity rather than to develop a skill or to learn a subject; and learning-oriented learners, most of whom are avid readers who pursue learning for its own sake" (Fitzgibbons, 1990, p. 19).

Implications. This line of learner-centered research suggests that selfdirected learners may share common traits and therefore may be identified by examining individuals' underlying qualities and characteristics. These findings have potential implications for organizational research. Provided future research confirms that individuals can be identified as self-directed learners, then these individuals can potentially be targeted for SDL programs at work. These individuals may possess qualities that predispose them to SDL and may, therefore, reap the greatest benefits from such programs.

Process-centered research has focused, in part, on the stages (or steps) of self-directed learning. Using semi-structured interviews, Brookfield (1981) studied 28 working class adults in England and found learners were able to set their own goals, obtain the necessary resources, and evaluate their own progress on a continual basis. Knowles (1975, p. 18) identified similar steps including: diagnosing learning needs, developing goals, identifying human and material 
resources for learning, choosing and implementing appropriate learning strategies, and evaluating learning outcomes.

However contrary to these findings, Spear and Mocker (1984), through interviews with self-directed learners, found that learning is not necessarily planned to the extent suggested by previous research. They found that individuals' life circumstances largely shaped the learning experience and drove the structure, method, resources, and conditions for learning. Their findings suggest learners do not proceed through these steps in a linear fashion.

Other process-centered research has focused on types of learning resources. As reported by Caffarella and O'Donnell (1987, p. 203), researchers have found that individuals use a variety of resources, both human and material, to engage in self-directed learning. Human resources include: peers (Kathrein, 1981), acquaintances (Shackelford, 1983), and other learners (Brookfield, 1981). Material resources include: libraries (Shirk, 1984), commercial radio (Bayha, 1984), and books, pamphlets, and newspapers (Hiemstra, 1976). And of course, the CDROMs and software programs supplied through individuals' computers, company intranets and extranets, as well as the Internet offer a multitude of options as well. This research demonstrates that individuals may pull from a variety of resources to engage in SDL. 
Implications. The majority of evidence suggests that people engage in the same series (or steps) that are typically used for training (i.e., needs analysis, setting learning goals, selecting materials, following the learning strategy, and evaluating learning). This aids organizations in the design of SDL programs and demonstrates that SDL programs are actually quite similar to typical training programs. Also, the research on learning resources shows just how rich the environment is for learning. Not all SDL programs need to be structured as self-study coursework. Employees can learn from a multitude of resources. Assessment Instruments: Self-Directed Learning Readiness

The study of individuals' readiness to engage in SDL has received a great deal of attention. Using self-report assessment instruments, researchers determine if individuals possess the attitudes and skills commonly associated with SDL readiness. Two such measures appear in SDL research. The most common measure, the Self-Directed Learning Readiness Scale (SDLRS) -- also known as the Learning Preference Assessment (LPA) when used in workshops focused on development -- was designed and modified by Guglielmino and associates (1977; Guglielmino \& Guglielmino, 1991) to gather data on individuals' learning preferences and attitudes toward learning (Guglielmino \& Guglielmino, 1991, p. 1). The other measure, Oddi's Continuing Learning Inventory (OCLI), is a less commonly used measure that also assesses whether individuals possess certain 
attributes commonly associated with self-directed learners: proactive drive, cognitive openness, and commitment to learning (Oddi, 1984).

Research on SDL readiness has taken one of two approaches (Brockett, 1985a). First, researchers have examined the correlation between SDL readiness and other psychosocial variables. SDL readiness has been shown to be positively related to creative thinking (Torrance \& Mourad, 1978), self-concept (Sabbaghian, 1980), conducting learning projects (Hassan, 1982), and life satisfaction (Brockett, 1985b). Second, researchers have used the SDLRS as a diagnostic tool to determine individuals' perceived readiness for SDL. For example, Savoie (1979) found scores on the SDLRS predicted nurses' success (i.e., grades) in continuing education courses.

Implications. SDL readiness appears to be a useful construct and may serve as an important individual difference variable as alluded to by Guglielmino (1977). However, research up to this point has been limited to correlational analyses. The usefulness of SDL readiness construct in organizational research requires further study to better determine how it relates to other individual and organizational variables.

\section{Criticism of the Field: Uniform Samples}

While there has been an extensive amount of research on SDL, especially SDL readiness, the samples used in these studies are primarily white, middle-class, 
educationally-advantaged adults (Brookfield, 1984, 1985; Caffarella \& O'Donnell, 1987). These researchers argue that more diverse samples should be studied such as working-class adults, older adults, and cross-cultural samples. While Brockett (1985) points to a handful that have studied either older adults and/or less formally educated adults studies (including Baghi, 1979; Brockett, 1983; Hiemstra, 1976; and Umoren, 1977), more research of diverse populations is needed. The present proposal sought to study SDL behavior among a diverse working adult population. As is shown, very little research has studied working adults especially in an organizational setting. Although Brockett (1985b) studied working class adults, he examined all types of learning projects (recreational and job-specific). The focus of the current research is work-directed SDL. In the next section, I review the scant SDL research that has occurred in work settings and lay forth a research agenda that may assist organizational researchers in their efforts to better understand how SDL operates in the workplace.

\section{Research on Work-Directed SDL}

Although Guglielmino and her colleagues have remarked that the principles of SDL may be applied to the work setting, only a handful of studies have tested this premise. Caffarella and O'Donnell (1991) studied how learners determine the quality of work-directed, SDL experiences by conducting focus group interviews with training and development specialists. Unfortunately, their chosen 
methodology (the depth interview) may have inadvertently prevented them from obtaining results that spoke to their research question. Respondents, in this case, chose to address the topic in such a way that the resulting data represents a discussion of how these individuals determined quality in general, not how they determine quality of SDL experiences. Five major themes emerged regarding participants comments on quality: "(1) Quality is judged on the basis of product and process; (2) Judgments of quality evolve over time; (3) The learner is the primary judge of quality; however, secondary sources of judgment were also important; (4) Quality is not a precise judgment, but has different variations and levels; (5) Quality has an affective component" (p. 21). This study represents an important early stride in work-directed SDL research and set out to uncover how individuals define SDL quality (i.e., successful SDL); however, these findings fail to reveal much insight into the definition or measurement of quality work-directed SDL.

In a subsequent qualitative study, Gerber, Lankshear, Larsson, \& Svensson (1995) uncovered different forms of SDL experiences in the workplace. Interviews with 21 white-collar workers of varying educational backgrounds from four different industries (an insurance company, trainers in a government department, a library, and a private educational institution) revealed six different forms of learning: (1) learning from mistakes and self-managed observations, (2) learning 
through interactions with others, (3) learning through formal training, (4) learning through training others, (5) learning through open lateral planning, and (6) learning through quality assurance. The researchers concluded that these findings demonstrate that workers learn on the job in a variety of ways some of which are, in fact, self-directed (p. 31).

Researchers have also begun to study the relationship between SDL readiness and job performance. Three quantitative studies have used the SDLRS to determine if differences in SDL readiness are related to differences in job performance. Guglielmino, Guglielmino, and Long (1987) studied 753 individuals (421 managers, 318 non-managers) from a large American utility company to determine if scores on the SDLRS were positively related to job performance in jobs that required either: (a) high levels of creativity and problem solving, (2) high levels of creativity, (3) high levels of problem solving, or (4) a high degree of change. Findings indicated that higher scores on the SDLRS were related to higher levels of job performance for all four types of job. However, two limitations of this study need to be addressed. First, performance measures were obtained from the participants themselves (i.e., prior to the training program, respondents were asked to provide their last performance rating - a single overall score). A more objective, timely measure of performance, such as supervisory ratings obtained at the time of study, would allow for stronger conclusions to be drawn. Second, participants were 
surveyed prior to entering a training program: no measures of improved performance due to training were obtained. Therefore, these results do not provide any insight into how SDL readiness may impact on-the-job performance.

Very similar results have been found in two other studies. In a study of 655 Hong Kong telephone company managers and supervisors, Roberts' (1986) results support the findings of Guglielmino, Guglielmino, and Long (1987). Individuals with higher scores on the SDLRS reported higher levels of overall job performance (i.e., last performance rating received), a higher degree of problem solving required in their jobs, a higher degree of creativity required in their jobs, and a higher degree of change in their jobs. As with the previous study, the job performance measure as well as the other measures of problem solving, creativity, and change were selfreport. Here, respondents were asked to indicate their perception of their last performance rating (i.e., "In my opinion my overall performance for the last rating period was": (a) outstanding, (b) very good, (c) satisfactory, (d) indifferent, (e) poor, or (f) don't know). Abbott and Dahmus (1990, as reported in Abbott \& Dahmus, 1992) also found SDLRS predicted performance, however, it did not distinguish between outstanding performers in jobs with high levels of creativity, problem-solving, and change as opposed to outstanding performers in other jobs. Both of these studies had similar limitations as was the case with Guglielmino, Guglielmino, and Long (1987). So while the results from these three studies 
suggest a strong relationship between SDL readiness and job performance, we must temper our conclusions due to some methodological problems such as self-report measures of performance, common method variance, non-random sampling, and potential social desirability effects (Abbott \& Dahmus, 1992).

Organizational researchers are always interested when they hear of a new variable that relates to job performance. However, this relationship needs to be explored in greater depth. Why does SDL readiness relate to job performance? The correlation between the two variables is interesting, however of greater relevance, is the process through which they are related. I propose that SDL readiness predicts job performance because individuals with a stronger preference for SDL engage in SDL activity, which results in increased learning, which then leads to heightened job performance.

In the next section, I provide a more detailed discussion of the proposed model along with supporting evidence for the hypotheses.

The Proposed Model

As presented earlier, I proposed the relationship between SDL readiness and job performance is mediated by SDL activity and learning. Specifically, I believe that individuals with a stronger preference for SDL (i.e., high on SDL readiness) would be more likely to engage in SDL than those low on SDL readiness, resulting in higher levels of learning than those who did not embark on SDL. The 
heightened learning then leads to enhanced job performance. In addition to SDL readiness, other variables were included in the theoretical model to capitalize on past psychological and organizational research (described below), thereby gaining a richer understanding of SDL in the workplace.

In this section, I define the variables in the model, explore the relationships between these variables and present the hypotheses. A control group was used to provide a stronger test of these relationships as reflected in the discussion below. Defining the Variables

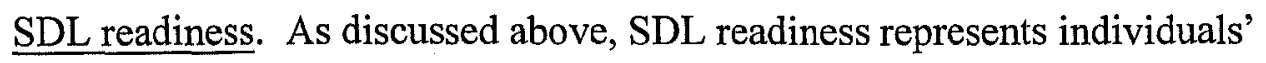
preferences for self-directed learning (e.g., self-study) as opposed to other-directed learning (e.g., teacher-centered classroom). The present study followed the work of Guglielmino and her colleagues (1977; Guglielmino, Guglielmino, \& Long, 1987) by focusing on individuals' perceptions of their own ability, willingness, and desire to engage in SDL. SDL readiness by no means assesses individuals' aptitude as a self-directed learner (i.e., this construct does not capture an objective measure of ability to engage and succeed in SDL activity but the individual's perception that they are capable of SDL). While aptitude for SDL probably shapes an individual's preference for SDL in part, ultimately it is that preference for SDL which drives the individual's decision to engage in SDL activity. 
Work Locus of Control. Locus of control (LOC) is "the extent to which a person perceives himself to control the events around him" (Broedling, 1975, p. 65, as cited by Cobb, 1986). As described by Rotter (1966), LOC represents the belief that individuals themselves, as opposed to external forces or chance, control or cause what happens to them. "Internals believe they are the primary determiners of their outcomes, whereas externals attribute their outcomes to external forces" (Ganster, \& Fusilier, 1989, p. 264). Spector (1988) responded to the need for domain-specific measures of LOC by creating the Work Locus of Control Scale (WLCS) specific to the work domain which include issues such as promotions, getting a job, dealing with one's boss, and job effort (Blau, 1993, p. 127). This measure determines the extent to which individuals believe these types of work events are controlled by their own actions (internals) versus other forces (externals).

Cognitive ability. Cognitive ability in this study refers to general intelligence or "g." The purpose is to assess "the level at which an individual learns, understands instructions and solves problems" (Wonderlic, 1999, p. 5). General cognitive ability has been shown to be a reliable, significant predictor of job performance and training performance across a wide array of jobs (Hunter \& Hunter, 1984; Neuman \& Wright, 1999; Pearlman, Schmidt \& Hunter, 1980; Ree, Earles, \& Teachout, 1994; Schmidt, Hunter \& Caplan, 1981; Sternberg, 1997; 
Wagner, 1997) and, hence, warranted study along side the other predictors of training success specified in the model.

Group membership. SDL activity could fall under many labels including: “independent learning, self-planned learning, self-instruction, autonomous learning, self-teaching, self-study, self-education, discovery learning, and the inquiry method" (Guglielmino, 1977, p. 6). As discussed above, SDL activity could entail a number of learning pursuits such as learning through interactions with others, learning through books or software, or learning by taking on new challenges. The present study does not distinguish between these different labels or define particular activities as more or less self-directed. Rather, the goal was to study one form of SDL activity and measure changes in individuals' performance as a result of that SDL activity. For sake of consistent measurement, the present research sought a SDL activity that represented a pre-designed self-study program where the learning objectives and materials were the same, but the individuals may move through the program at their own pace. The targeted SDL activity was an on-line self-study listening skills course. Respondents were either enrolled in this course (the participant group) or not (the control group).

Other SDL activity. While the present study focused on the enrollment, learning and subsequent performance of the targeted listening skills course, opportunities for other types of SDL activity are bountiful. Adult education 
researchers have found more than $90 \%$ of individuals engage in some type of SDL activity each year. SDL activities could include other means for developing ones own listening skills. Individuals may also pursue SDL activities for other workrelated skill development (e.g., project planning, time management, Excel skills, coaching others) or for their own personal interests and hobbies (e.g., cooking, yoga, learning another language). Other SDL activity could take any number of forms including books, audio tapes, CD-ROMs, or on-line learning for example. The purpose of this variable was to capture individuals' involvement in other SDL activities outside of the targeted listening skills course.

Extent engaged in SDL course. While the group membership variable reflects who has elected to engage in the course, it does not assess the extent to which individuals engaged in the SDL course. The listening skills course had a number of features that individuals may or may not fully utilize. Specifically, how much material was covered may vary. Some may have taken advantage of the extra features such as video demonstrations of listening skills or additional tips and links. Others may have taken the unit tests at the end of each section and then reviewed material based on the results. And finally, some may have more actively practiced key learnings on-the-job as recommended. The extent to which individuals engaged in the course is an important aspect of SDL activity for it looks more deeply at the degree to which they took SDL opportunities and it allowed the 
present study to examine its impact on learning and subsequent performance. The variable was considered within the participant group only to provide a more sensitive measure of SDL activity within a specific type of activity.

Learning. Learning refers to the amount of information learned by the individual in the SDL program. Learning was measured at the completion of the SDL activity. While Kraiger, Ford, and Salas (1993) identify three categories of learning outcomes: cognitive (i.e., knowledge acquisition), skill-based (e.g., skill acquisition), and affective, the type of learning outcome examined in the present study was driven by the SDL activity and took the form of a cognitive measure. The SDL program focused on knowledge acquisition such that individuals were presented with material on listening skills and then tested on the amount of information retained (e.g., "What is an example of an external distraction?").

Performance. Changes (i.e., improvement) in two types of performance were of interest in the present study: overall performance and performance specific to the learning objective (i.e., listening skills). Overall job performance refers to what is typically assessed at an employee's annual or semi-annual performance review: level of performance on a whole, across various dimensions. Listening skills performance is a narrower construct that assessed the employee's listening skills performance on-the-job. Hence, specific performance represented a more narrow measure of performance that was in direct alignment with the learning 
objectives of the SDL activity. Changes in the level of overall performance and specific performance after the SDL activity were examined. Antecedents to SDL Activity

Research on antecedents to SDL activity has been limited. The present study focused on three antecedents: SDL readiness, work locus of control, and cognitive ability. In this section, the relationship of each antecedent to the three measures of SDL activity (group membership, other SDL activity, and extent engaged in course) is discussed.

SDL Readiness. Research on SDL readiness has typically been correlational (e.g., individuals with higher SDL readiness scores engage in more learning projects; Hassan, 1982) without use of random assignment and control groups to show effects between those engaged in SDL and those who were not (e.g., does SDL readiness predict enrollment in and use of SDL activity). Given that SDL readiness assesses individuals' preference for SDL, it follows that individuals with a stronger preference for SDL would engage in a voluntary SDL program (as well as other SDL activity) than individuals who do not prefer SDL. Thus:

Hypothesis 1: SDL readiness scores will predict individuals involvement in SDL activity such that individuals with higher SDL readiness scores will be engaged in the listening skills SDL course, whereas individuals with lower SDL readiness scores will not. 
Hypothesis 2: SDL readiness scores will be related to other SDL activity such that individuals with higher SDL readiness scores will report a greater amount of other SDL activity than individuals with lower SDL readiness scores.

It also follows that individuals with a stronger preference for SDL would be more comfortable with this type of activity and eager to take advantage of the various opportunities to learn and acquire more skills and knowledge. Therefore:

Hypothesis 3: Individuals with higher SDL readiness scores will engage in the listening skills SDL course (i.e., cover more materials, take advantage of extra features and information, review material and test their progress and end knowledge, as well as practice new learnings on the job) to a greater extent than individuals with lower SDL readiness scores.

Work Locus of Control. Locus of Control (LOC) has been related to many work-related variables, including: job satisfaction, commitment, intention/turnover, autonomy, motivation, effort, job performance, influence, role stress, initiating structure/leadership style, salaries and raises (Kinicki \& Vecchio, 1994; Macan, Trusty \& Trimble, 1996; Nystrom, 1983; Spector, 1982, 1988). For example, internals have been found to be more satisfied with their jobs, more 
committed to their organization, more intrinsically motivated to do well on the job, remain on the job longer, and receive higher salaries and wage increases. Recently, Coleman, Irving \& Cooper (1999) examined the commitment finding further to reveal internal LOC was related to affective commitment (i.e., individuals stay with the organization because they are psychologically attached to the organization) and external LOC was related to continuance commitment (i.e., individuals stay with the organization because the costs associated with leaving are too high or they lack alternatives). Past research, in sum, has confirmed that internals "are more confident in their ability to influence their environments and to control their own destinies and are more likely to do so" (Howell \& Avolio, 1993, p. 900).

In an interesting study closely related to the focus of the present study, Blau (1993) following the work of Katz and Kahn as well as Spector (1982) examined relationships between LOC and compliant performance (i.e., productivity) versus innovative, spontaneous performance (i.e., self-development). Blau states:

"One category of innovative and spontaneous behavior is self-training (Katz, 1964; Katz \& Kahn, 1978). Self-training examines the degree to which members spend time and energy mastering knowledge and skills either for doing their own jobs better or for preparing to advance in the organization. Katz (1964) notes that there may or may not be a requirement 
that employees self-train, but that such a performance dimension is more voluntary or initiative-based as opposed to compliant" (Blau, 1993, p. 126). Blau's findings were consistent with Spector's (1982) prediction that internals would be more suitable for tasks that require initiative whereas externals would be more suitable for tasks that require compliance. Specifically, Blau found that internal LOC in the work domain was positively related to initiative performance (i.e., self-development - innovative, spontaneous behavior beyond the scope of the individual's job) and external LOC was positively related to compliant performance (i.e., productivity - performance in given role requirements). Hence, internals engaged in self-development to a greater extent than externals. Internals also actively seek information to a greater extent than externals (Lefcourt \& Wine, 1969). Other researchers have found that internals perceive more opportunities than externals to control their work situation and possess higher expectancies that effort will increase job performance which will, in turn, result in rewards (Brodeling, 1975; Evans, 1974; Kimmons \& Greenhaus, 1976; Lied \& Pritchard, 1976; Szilagyi \& Sims, 1975; as cited in Ganster \& Fusilier, 1989).

The present study posited that internals, given their beliefs that they can alter their own rewards, reinforcements or outcomes (Spector, 1988) with action, would be more likely than externals to take control of their own learning to improve their job skills and performance. As a result: 
Hypothesis 4: Individuals with stronger internal LOC scores in the work domain will predict membership in the current SDL participant group. That is, internals will be more likely to engage in the on-line listening skills course than externals.

Hypothesis 5: Individuals with stronger internal LOC scores in the work domain will also predict other SDL activity. That is, internals will be more likely to engage in a greater amount of other SDL activity than externals.

Once enrolled in the listening skills course, it is believed that internals will maximize the resources available to them to acquire as much new learning as possible to positively impact their learning and subsequent job performance. Externals enrolled in the listening skills course, on the other hand, will not utilize the course fully given their belief that external factors will determine the outcomes regardless of learning these new skills.

Hypothesis 6: Internals will engage in the course (i.e., cover more materials, take advantage of extra features and information, review material and test their progress and end knowledge, as well as practice new learnings on the job) to a greater extent than externals: Cognitive ability. As stated above, cognitive ability or "g" is a powerful predictor of training success and job performance across jobs. But why? 
Researchers believe measures of cognitive ability provide insight regarding individuals' trainability, adaptability to situations as they arise, problem solving ability, and even satisfaction with the demands of the job (Wonderlic, 1999, p. 5). Brody (1997) suggests that general intelligence is related to acquisition of job knowledge. It follows then that individuals with greater cognitive ability, acquire more job knowledge providing themselves with greater KSAs which, result in better performance. Thus, the current study explored learning, more specifically self-directed learning, as a mediator of the cognitive ability-performance relationship. Individuals with higher cognitive abilities have a greater capacity for learning than those with lower cognitive abilities - they are able to acquire more knowledge from various experiences including formalized training and on-the-job experiences as well as less organized training situations (Wonderlic, 1999, p. 17). Individuals with a greater capacity to learn can better reap the benefits of learning achieving better job performance and subsequent rewards. As a result, these individuals should be more likely to seek out and take advantage of opportunities to acquire more job knowledge and skills. Therefore:

Hypothesis 7: Individuals with higher cognitive abilities will be more likely to choose to participate in the listening skills course than individuals with lower cognitive abilities. 
Hypothesis 8: Similarly, individuals with higher cognitive abilities will be more likely to engage in other SDL activities than individuals with lower cognitive abilities.

Finally, individuals with higher cognitive skills are better able to extract useful information from multiple resources as well as process material more efficiently. Therefore, when presented with a self-directed training course with several different means for learning, these individuals should be more likely to engage in the full range of course offerings.

Hypothesis 9: Individuals with higher cognitive abilities will engage in the course (i.e., cover more materials, take advantage of extra features and information, review material and test their progress and end knowledge, as well as practice new learnings on the job) to a greater extent than individuals with lower cognitive abilities.

The Relationship between SDL Activity and Learning

Group membership. Individuals should achieve greater learning through SDL activity than no learning activity at all, however, the researcher was unaware of any existing empirical evidence. While rigorous empirical support demonstrating the connection between SDL activity and learning is lacking, there is widespread use of SDL programs across organizations. It is difficult to believe 
these programs would be so widely utilized if they were believed to be ineffective learning systems. Therefore, the current researcher hypothesized:

Hypothesis 10: Individuals who engage in SDL activity (the participant group) will show higher levels of learning than individuals who do not engage in SDL activity (the control group). Other SDL activity. While other SDL activity most likely increases the acquisition of job knowledge (i.e., learning), the present study focused exclusively on learning related to listening skills. Therefore, only other SDL activities focused on developing one's listening skills would be relevant here. Just as one would expect the listening skills course to increase learning, other SDL activities targeted at listening skills development should also increase learning. Thus:

Hypothesis 11: Individuals who engage in a greater amount of other SDL activity focused on listening skills development between time 1 and time 2 will show higher levels of learning than individuals who engaged in less other SDL activity focused on listening skills during this time period.

Extent engaged in course. Individuals who utilized the listening skills course more fully should have acquired greater listening skills. These individuals would have covered more material, used extra features to 
acquire more information, participated in interactive exercises to rehearse new skills, tested their knowledge while going through the course, and practiced their new skills on-the-job. Hence, richer use of the course would result in greater learning.

Hypothesis 12: Individuals who engage in the listening skills course to a greater extent will exhibit higher levels of learning than individuals who engage in the course to a lesser extent. The Relationship between Self-Directed Learning and Job Performance

As discussed previously, past research has examined the relationship between SDL readiness and job performance, but it has not examined the relationship between SDL and performance. While organizations implement SDL programs on the assumption that these activities develop individuals and improve job performance, there is little empirical evidence to support this assertion. Logic suggests that individuals who do not learn the new material cannot apply it to their job and thereby will have difficulty improving their performance in those areas. For example, individuals who do not learn effective listening skills would have difficulty improving these skills. However, those individuals who acquire new learning are able to improve their job performance as a result of their newly learned knowledge, skills or abilities. 
Hypothesis 13: Individuals who learn more will show greater improvement in their performance.

The hypothesis above considers learning across both groups. In addition to the between-group comparison, a thorough test of the learning-performance relationship requires examining within-group effects as well. Individuals engaged in the same training vary in terms of how much they learn. As stated above, individuals who learn new material should be better able to improve their performance based on their newly acquired learning. It follows then that individuals who learned more than others in the SDL program would have more enhanced knowledge, skills or abilities and, therefore, may enhance their performance to a greater extent. So individuals that exhibit the greatest learning should show the greatest increase in job performance.

Hypothesis 14: In the SDL participant group, individuals who learn more will show a greater increase in their performance than individuals with lower learning scores.

And finally, earlier a distinction was made between overall job performance and performance specific to the learning objective. Learning should be more strongly related to listening skills performance than overall performance because learning and specific performance were aligned to measure the same skill/competency: listening skills. Learning assessed the extent to which 
individuals acquired the knowledge of listening skills; specific performance assessed the extent to which individuals used these listening skills well on the job.

Hypothesis 15: The relationship between learning and listening skill-specific performance will be stronger than the relationship between learning and overall performance.

The relationship between learning and overall performance was expected to be significant because specific performance makes up a part of the overall score. So why study overall performance? This study sought to explain, in part, the relationship between SDL readiness and overall performance found in previous research. Thus, by examining the relationship between learning and specific performance, the effectiveness of the SDL program could be evaluated. However, examining the relationship between learning and overall performance was necessary to explain the correlation between SDL readiness and performance found in previous research.

\section{Summary}

Our rapidly changing work environment drives the need for individuals to be more self-directed in their learning. Yet, research on work-directed SDL is still in its infancy. The proposed model sought to expand on our current knowledge of SDL in the workplace and past research by explaining the processes by which SDL 
readiness and related psychological variables related to job performance (through SDL activity and learning).

The proposed study examined one specific SDL program in an organization utilizing a control group to provide a solid test of the hypotheses. Studying the effects of a particular SDL program on learning and performance as opposed to a wide range of SDL activities allowed for two major benefits. First, it allows for a clear evaluation of the SDL program's effectiveness, something currently lacking in the literature. Second, it provides the opportunity to examine changes in learning and performance as a result of one consistent experience. 
Method

\section{$\underline{\text { Research Design }}$}

The proposed model was tested using a pretest-posttest control group design:

$$
\begin{array}{ccccc}
R & \mathrm{O}_{1} & \mathrm{X}_{2} & \mathrm{O}_{3} \\
R & \mathrm{O}_{4} & \mathrm{O}_{5} & \mathrm{O}_{6}
\end{array}
$$

A control group (i.e., a group of individuals not currently engaged in SDL activity) allowed for stronger tests of the proposed model by ruling out rival hypotheses (i.e., threats to internal validity) such as history, maturation and testing (cf. Campbell \& Stanley, 1963). Also, the use of a control group allows for comparisons between the experimental and control groups. ${ }^{1}$ For example, SDL readiness scores were compared between individuals engaged in SDL and those who did not.

\section{Sample of Participants}

One organization participated in this study, which allowed for the control of differences across organizations (different performance standards, learning cultures,

\footnotetext{
${ }^{1}$ A second participant group was sought in which individuals would be participating in the course but at a later date. This group would have allowed the researcher to examine differential performance ratings between participant groups and control groups, based not on true changes in performance, but mere enrollment in the course. However, such a group was not available for study.
} 
access to training, etc.). The organization was a large financial services organization based in the northeast with a number of offices across the U.S. The organization regularly provides its employees with access to a number of on-line self-study courses. The programs are strictly voluntary and require only their immediate supervisor to approve course enrollment.

The respondents for this research were determined based on the target audience for the on-line listening skills course: first-level managers. The organization provided the researcher with individuals' names as they enrolled for the course. A control group was chosen randomly from a list of front-line managers who were not (and had not been) enrolled in this course. A total sample size of 262 was obtained - 131 were in the participant group, 131 were in the control group.

The average respondent was male ( $68.7 \%$ male vs. $23.7 \%$ female), white (82.8\% white/Caucasian vs. $9.6 \%$ other), college educated ( $42.7 \%$; ranged from high school/GED to graduate degree), between $30-39$ years old $(84.7 \%$; ranged from approximately $19-59$ years old), employed for 2.63 years within the organization (ranged from $1 / 2-11$ years), worked an average of 53.51 hours per week (ranged from $40-80$ hours), earned between $\$ 40,000$ - $\$ 49,000$ per year (36.6\%; ranged from under $\$ 30,000$ to $\$ 59,999)$, was married (41.2\%), and had one child under the age of 18 (50.8\%; ranged from $0-4$ children). The two groups 
differed significantly on only three demographic variables: gender, hours worked per week, and number of children. The participant group had a smaller percentage of women $(\underline{F}(1,240)=15.48, \mathrm{p}<.001)$, worked fewer hours per week $(51.99$ versus 55.03 hours; $\underline{\mathrm{F}}(1,240)=5.63, \mathrm{p}<.05)$, and had fewer children on average $(0.47$ versus $1.31 ; \underline{F}(1,240)=38.35, \underline{p}<.001)$.

\section{Listening Skills Course Description}

The participating organization offers a number of different courses on their intranet for employees (both managers and non-managers) to develop skills. These courses range from enhancing technical capability (e.g., how to use Word, Excel, PowerPoint, $\mathrm{C}++$ programming) to resource management (e.g., time management, project management, people management) to softer skills (e.g., listening skills, relationship building, influencing others). Employees may elect to take any course at any time as long as consent has been provided by their manager. Typically, enrollment for courses is highest during and immediately following their performance review and development planning process.

The listening skills on-line self-study course was chosen for a number of reasons. One, this course was relatively new so the organization was particularly interested in receiving some evidence as to its impact on individuals and the organization. Two, the course was introduced to coincide with the performance management and development planning review process, so anticipated enrollment 
met sample requirements. Three, unlike other courses that could be taken in less than two hours, the listening skills course consisted of multiple sections to be taken over the course of several weeks, allowing for self-directed behavior to be studied as a longer-lasting quality (or characteristic) as opposed to more of an impulse (or good intention).

The course consisted of eight sections. Students were encouraged to complete one section per week to allow opportunities to concentrate on new learnings and practice them at work prior to completing the next section. The eight sections included: the introduction (and self-assessment), bad listening habits, central listening skills (e.g., overcoming distractions, recognizing central ideas), critical thinking I (e.g., evaluating support for and evidence of message), critical thinking II (e.g., detecting fallacies in arguments, weighing inferences drawn), active listening skills I (e.g., asking open-ended questions, paraphrasing, using supporting nonverbals), listening skills II (e.g., reflecting feelings of others, building on others' comments), and the conclusion/summary (and mastery quiz). Each section was estimated to take between $20-45$ minutes depending on the extent to which students used all of the course features available. Specifically, the course featured basic content which was narrated (or could be read without the use of a narrator), video clips to provide vignettes that illustrate key learning points, interactive exercises that students could complete (e.g., listen to a speaker and then 
answer questions regarding the central ideas of the message), and unit tests at the end of each section. In addition, students could click on different links to obtain additional information on a topic from other websites or gain extra tips on a given point. At the end of each section, students were encouraged to practice the learnings from the individual section before completing the next section. So time for completion ideally ranged between six to eight weeks.

Measures

The Self-Directed Learning Readiness Scale (SDLRS)/Learning Preference Assessment (LPA). The SDLRS scale, referred to as the LPA in developmental activities, was developed by Guglielmino (1977), then adapted slightly. The measure was designed to gather data on individuals' learning preferences and attitudes toward learning (Guglielmino \& Guglielmino, 1991, p. 1; as cited in Delahaye \& Smith, 1995). The measure, as shown in Appendix A, contains 58 items such as "I know when I need to learn more about something" and "No one but me is truly responsible for what I learn." Responses range from 1 ("Almost never true of me") to 5 ("Almost always true of me"). The reliability and validity of the instrument have received substantial support in subsequent research (Guglielmino, 1989).

However, the SDLRS has been criticized on several issues. Field (1989) argued that few studies have focused on statistical validation of the instrument. 
Those that have focused on validation have been qualitative and conceptual in nature. Field criticized Guglielmino's use of the Delphi technique to generate agreement on the items, the lack of a clear conceptual definition of SDL readiness or the self-directed learner, and the use of negatively phrased items. Guglielmino (1989) responded with good explanations to all of these issues. She stated that: (1) the Delphi technique was used to generate consensus on the characteristics of the self-directed learner, not consensus on the final set of items; (2) a definition of SDL readiness and the self-directed learner were not included to prevent researcher bias; and (3) the use of reverse items allows the researcher to ensure that individuals are completing the scale meaningfully.

Field (1989) also addressed the issue of whether SDL readiness is a homogeneous or multidimensional construct. The 8 factors found by Guglielmino are often ignored in research; researchers just use the overall SDLRS score. In his study of 244 students, Field found four, not eight, factors. The first factor (love and/or enthusiasm for learning) explained the majority of the variance (17.6\%) with the other three factors each explaining less than $5 \%$ of the variance. Therefore, Field (1989) questioned whether this scale is a measure of readiness at all, or just an assessment of individuals' love of learning. Based on these results and the results of another study (West \& Bentley, 1989; as cited in Field, 1990), Field (1990) concluded that the construct is in fact homogeneous. Although researchers 
commented on the limited sample used by Field (Long, 1989) and some misunderstandings of the factor analytic techniques Field employed (McCune, 1989), the point raised by Field is a good one. Is SDL readiness a homogeneous or multidimensional construct? Typically researchers use the overall scale score implying it is homogenous, yet these factors are frequently discussed. More research on the presence and meaning of these factors is required. If it is a homogeneous construct, is it tapping SDL readiness or simply a love of learning, as suggested by Field $(1989,1990)$ and Bonham (1991)? Delahaye and Smith (1995) refute this claim by demonstrating the convergent validity of the SDLRS by correlating with a related scale, the SOQ's Andragogy scale, which assesses students' preferences for responsibility of their own learning. This finding indicates that the SDLRS relates more closely to the concept of SDL than it does to a love of learning. Additionally, Delahaye and Smith's study provides a statistical validation study of the SDLRS previously lacking as argued by Field (1989). Researchers have also expressed concern regarding the appropriateness of using the SDLRS on a diverse population. Most validation research has focused on academic, generally graduate-level, samples. Some research has indicated that the SDLRS may not be suitable for working class adults (Brookfield, 1985), or for older adults or less educated individuals (Brockett, 1985). Brockett found that many older adults had difficulty with the measure because the SDLRS emphasizes 
schooling and book learning, things that may be less relevant in their current lives. However, the validation study discussed above (Delahaye \& Smith, 1995) addressed this concern as well. These researchers demonstrated that the SDLRS has acceptable reliability $(\alpha=.72)$ and construct validity for individuals over 20 years of age. (They suggest that younger populations may not yet have developed a preferred style of learning.) However, they caution that more research is needed that replicates these finding in various professions, disciplines, and with the educationally disadvantaged.

While Field and others raise numerous issues regarding the appropriateness and use of the SDLRS, evidence refuting their criticisms has been supplied by a variety of researchers. The SDLRS remains a widely accepted and frequently used measure.

In the current study, the SDLRS exhibited good reliability with a reliability coefficient (Cronbach's alpha, $\alpha$ ) of .91. A factor analysis was performed to examine any underlying sub-scales as found in other studies. Results support a unidimensional scale. A principal components factor analysis found three factors with eigenvalues greater than 1 . The first factor, with an eigenvalue of 34.75 , accounted for $59.9 \%$ of the variance in the scale. The second factor, with an eigenvalue of 1.34 , accounted for only $2.3 \%$ of the variance. The third factor, with an eigenvalue of 1.07 , accounted for only $1.9 \%$ of the variance. However, the 
factor loadings of the 58 items confirmed strong loadings on the first factor with no item loading cleanly on the second or third factor (i.e., no item had a loading on factor 2 or 3 that exceeded .30 while having a loading of less than .30 on factor 1 ). A varimax rotation was performed, however, still very few items (i.e., 8 out of 58) loaded cleanly onto separate factors. The remaining items double- or triple-loaded onto the factors. With a lack of a clear underlying factor structure, the present research utilized a single overall scale score to remain consistent with past research. Work Locus of Control Scale (WLCS). The WLCS was created by Spector (1988) to develop a work domain-specific measure of LOC. The scale (See Appendix B) consists of 16 items that were found to best relate to work behavior, show no significant relationship with social desirability, and balance internal and external items (i.e., 8 each). Respondents report their agreement with the 16 statements (e.g., "promotions are given to employees who perform well on the job") on a 6-point scale ( 1 = disagree very much, 2 = disagree moderately, $3=$ disagree slightly, 4 = agree slightly, 5 = agree moderately, 6 = agree very much). An average overall scale score is calculated after reversing the appropriate items. A low score reflects internality; a high score reflects externality.

Since the creation of the scale, some researchers have questioned if it is truly unidimensional or if internal and external subscales should be used instead. Macan, Trusty \& Trimble (1996) found evidence to support a two factor model. 
However, while Coleman, Irving and Cooper (1999) found that a two factor model was a better fit for the data, it was not significantly better than a one factor model. To explore the dimensionality of this scale in the current study, the reliability coefficient was examined and a factor analysis was performed. The coefficient alpha obtained in the present study was $\alpha=.90$. A principal components factor analysis extracted one factor with an eigenvalue greater than one (eigenvalue $=$ 12.01 ), explaining $75.1 \%$ of the variance, supporting Spector's original intention of the scale as unidimensional. Therefore, a single overall scale score was employed for all subsequent analyses.

Cognitive ability: the Wonderlic Personnel Test. The Wonderlic Personnel Test (WPT) consists of 50 questions arranged in order of increasing difficulty that cover a wide array of problem types (e.g., word comparisons, sentence parallelism, following directions, number series, analysis of geometric figures and story problems) developed from Wonderlic and Hovland (1939). The WPT, a 12-minute timed test with alternate equivalent forms, has been used in business and industry for over 60 years. The average score across job applicants is 21 as reported by Wonderlic (1999). The test assesses general cognitive ability (or general intelligence, "g") and has been shown to correlate with other similar cognitive ability measures including the Wechsler Adult Intelligence Scale (Dodrill, 1981, Hawkins et al., 1990), the cognitive or "Aptitude G" scale of the General Aptitude 
Test Battery (GATB Manual, 1970), and the "Academic" scale of the Armed Services Vocational Aptitude Battery (Hunter, 1989) (c.f. Wonderlic, 1999, pp. 19 for complete information on validity of scale).

The test score was the sum of correct responses (i.e., possible range of 0 50). Martocchio and Judge (1997) identified the Kuder-Richardson (KR-20) coefficient (see Cascio, 1991), as the proper measure for internal consistency for tests whose items are dichotomously scored. The KR-20 in the current study was .57. However, given the timed nature of this test, the KR-20 does not serve as the most effective measure of reliability. The Wonderlic manual (p. 21) provides a number of reliability statistics including test-retest reliabilities which have ranged from .82 to .94 ; longitudinal reliability of .94 ; alternate form reliabilities ranging from .73 to .95 ; and split-half reliabilities ranging from .88 to .94 .

Group membership. This variable was not a measure for inclusion in the surveys. It was a dichotomous variable to represent the group for each individual. Individuals enrolled in the on-line listening skills course were in the SDL participants group and coded " 1 " and individuals in the control group were coded "2." In other words, these values represented whether or not the individual engaged in the on-line listening skills SDL program.

Other SDL activity. This study focused on one particular SDL program; however, that does not preclude the possibility that individuals were engaged in 
other SDL programs during the course of this study. For example, individuals may have engaged in SDL for time management or grant writing. In an effort to examine for the influence these additional programs may have on overall performance, individuals were asked to indicate what other SDL activities they engaged in over the past year (at time 1) and since the first survey administration (at time 2). The measure asked respondents to report the what extent they engaged in 16 different types of SDL to develop their (a) listening skills, (b) other workrelated skills, and (c) skills for personal interests or hobbies. For each type of skill development, respondents were asked to indicate on a scale from 1 ("to no extent") to 5 ("to a very great extent") they used each of the following 16 activities: books, audiotapes, videos, CD-ROMs, on-line internet courses, other internet resources, LISTSERVs, seminars, workshops, conferences, classroom-based learning, correspondence courses, on-the-job training and/or development, help from mentor, help from others, or other SDL activity.

The data was recoded from the 1-5 scale to a $0-4$ scale so that a score of zero reflects no SDL activity. That is, only individuals who have engaged in some SDL activity will obtain a score greater than zero. Average scale scores were taken to calculate an "other SDL activity" average for listening skills, other work-related skills, and skills for personal interests both at time 1 and time 2 . Given the nature of these scale scores, Cronbach's alpha is not a meaningful measure. Instead, the 
average intercorrelations among the items were calculated for each scale to ensure the items were positively correlated (i.e., working in the same direction). If items were strongly negatively correlated with the other items (e.g., higher instances of book use to develop listening skills at time 1 was negatively related to using on-thejob activties to develop listening skills at time 1), that item would be excluded from the scale.

For other SDL activity (listening skills, time 1), the item intercorrelations ranged from .43 to -.03 with an average intercorrelation of .17 . For other SDL activity (listening skills, time 2), the intercorrelations ranged from -.004 to -.01 with an average intercorrelation of -..01. For other SDL activity (other work-related skills, time 1), the intercorrelations ranged from .43 to -.06 with an average intercorrelation of .23. For other SDL activity (other work-related skills, time 2), the intercorrelations ranged from .34 to -.04 with an average intercorrelation of .02 . For other SDL activity (personal interests, time 1), the intercorrelations ranged from .33 to -.06 with an average intercorrelation of .18. And for other SDL activity (personal interests, time 2), the intercorrelations ranged from -.01 to -.02 with an average intercorrelation of -.01 .

Note that time 2 scales exhibited a narrower range and lower average intercorrelations. This indicates less variability in the use of other SDL activities at time 2 than time 1, probably as a result of the time period captured. Time 1 asked 
respondents to report other SDL activities over the past year; time 2 asked respondents to report other SDL activities since they completed the time 1 survey (approximately 2 to 4 months). Given the low variability of time 2 scales, time 1 scales were uscd to test the hypotheses predicting other SDL activity (hypotheses 4, 5 , and 6)

Extent engaged in course. In an effort to examine degree of self-directed activity, a measure was constructed to examine the extent to which individuals in the listening skills course utilized the various features of the course. The more a person used the different features, the more material that person was exposed to. Individuals were asked to indicate the extent (1-5 scale as reported above) to which they used various features of the listening skills course (i.e., reading/listening to the material, watching video demonstrations, completing the interactive exercises, reviewing material more than once, reviewing key learning points at the end of a section, completing the mastery quiz, reading additional tips, linking to other related sites, and practicing learning points on-the-job). As with other SDL activity, the data was recoded from 1-5 to $0-4$ such that engaging in a particular feature of the course "to no extent" resulted in a score of zero. As a result, scores greater than zero reflect some SDL activity (i.e., use of course features). A total score was obtained by combining these items in a specific way determined logically, not statistically. Although this measure was not constructed 
to contain subscales, clustering some items together into subsets and then taking the average of these subsets provided more meaningful data then averaging all the items together. The overall extent engaged in course scale score was obtained by averaging together material covered, using extra features (i.e., video demonstrations, tip features, exploring related links), reviewing material, taking the tests and interactive exercises, and practicing new skills on-the-job. The reliability coefficient obtained from these five subscales is .82 . (Note: The reliability coefficient from the items, without combining them into subscales, is also .82.)

Learning measure. The listening skills course contained pre- and post- selfassessments that were used for the baseline measure at time 1 and the learning measure at time 2. Each measure consisted of 20 items that asked respondents to circle the correct answer. The items tapped material that related to listening skills and were covered in the self-study course. Example items include: "Which is not an example of an external distraction?" (response choices: noise, heat, vocabulary of speaker, feeling tired) and "Which of the following demonstrates active listening?" (response choices: rocking in chair, nodding, arms crossed in front of chest, asking yes/no questions). The two measures were distinct; that is, they did not contain overlapping items. Scores were calculated by summing the number of correct responses for each measure. 
Overall job performance. Each employee's immediate supervisor responded to a 6-item scale used by the Office of Personnel Management in several validation studies (Conn; 1997; Holke, 1995). As outlined by Holke, this performance measure assessed the employee's ability to: (a) use time efficiently and work properly; (b) do quality work; (c) avoid mistakes; (d) understand the principles, cquipment, materials, and methods of his or her work; and (e) handle several different operations. The sixth item was a summary rating of the employee's performance. The performance measure, following Holke's method (and used in Conn, 1997), is presented in Appendix C.

Supervisory performance ratings were collected for both groups prior to the SDL program to establish a baseline and three months after participants finished the program to determine how much their performance improved. Three months was the chosen interval because enough time must be allowed for individuals to exhibit their newly acquired knowledge or skill on the job; however, too much time allows for too many other factors to enter in and could contaminate the findings (e.g., other training programs, changes in job role, restructuring). The reliability of this scale was good ( $\alpha=.90$ at time $1 ; \alpha=.89$ at time 2$)$.

Performance specific to listening skills. A measure was constructed to assesses individuals' listening skills. The measure consisted of 4 items that asked supervisors to rate their employees': (a) listening skills overall, (b) ability to 
comprehend information presented, (c) demonstrate that others' comments have been heard, and (d) use nonverbals to communicate active listening (see Appendix D). The reliability of this scale was fairly good ( $\alpha=.82$ at time $1 ; \alpha=.83$ at time 2).

A fifth item was included that asked supervisors to rate the importance of listening skills for their employee's job, however, this item was not part of the overall listening skills rating. The importance item was added after the conceptual model was developed and, therefore, was included only as an exploratory variable.

This measure was collected for both groups at the same time as overall job performance (i.e., prior to the listening skills SDL program and three months after its completion).

Demographics. A number of demographics were included including: gender, age, race, education, tenure, income, hours worked per week, marital status, number of children. Gender was coded "1" for male and "2" for female. For age, respondents indicated their age within 10-year age brackets, for example, 30-39 years old. Race was coded "1" for Asian, "2" for Black/African, "3" for Hispanic, "4" for White/Caucasian, and "5" for other. Education was coded using six levels ranging from "Some high school" to "Graduate degree." Tenure was measured as the number of years the individual has been employed by the organization. For income, respondents indicated their income within $\$ 10,000$ brackets, for example, 
$\$ 30,000$ - $\$ 39,999$. Hours worked per week was measured as average number of hours reported by respondents. Marital status was coded " 1 " for single, " 2 " for married, "3" for divorced, and " 4 " for widowed. Number of children was measured as the number of children under the age of 18 as reported by the respondents. $\underline{\text { Data Collection }}$

Data was collected for both the SDL participant group and the control group before the listening skills SDL program (Time 1), immediately after the listening skills course (Time 2), and three months after the course was completed by the individual (Time 3).

At Time 1 (pretest), both the participant and control groups were surveyed to determine individuals' SDL readiness and their current level of listening skills knowledge (to obtain a baseline measure). Also, supervisors provided overall performance and listening skills-specific performance ratings for both groups. At Time 2 (posttest), both groups again received the SDL readiness measure to examine changes in SDL preferences after engaging in the listening skills SDL program and the learning measure to determine how much was learned as a result of the listening skills measure. At Time 3 (post-posttest, 3 months later), supervisors provided overall performance and specific performance ratings for both groups. At both rating periods, supervisors were not informed as to which employees were enrolled in the listening skills to prevent bias. 
Efforts were made to match the participant and control group in terms of position (first-level supervisors were used for both) and time lag between survey administration. When participants enrolled in the course, control group respondents were surveyed as close to the same time as possible. When participants completed the course and were re-surveyed, the same number of individuals from the control group were surveyed as close to that time as possible. For instance, if 12 participants took 2 weeks to finish the course, 12 individuals from the control group were surveyed 2 weeks after completing the first questionnaire.

\section{Data Analyses}

Multiple regressions were performed to test the hypotheses described above. For learning and performance measures, the effects of their respective time 1 scors were covaried out. In addition, the role of SDL as a mediating variable between the antecedents (SDL readiness, locus of control, and cognitive ability) and performance were examined following the classic mediation model. First, performance was regressed on SDL readiness. Performance was then be regressed on SDL readiness and learning. If the observed relationship between learning and performance is significant and the relationship between SDL readiness and performance is no longer significant, then learning is a mediating variable following the classic mediation model. 


\section{Results}

\section{Zero-order Correlations}

The zero-order correlations reveal preliminary support for a number of the hypothesized relationships above. SDL readiness was significantly related to group membership $(\mathrm{r}=-.28, \underline{\mathrm{n}}=242, \mathrm{p}<.001)$ such that individuals with a stronger preference for SDL were more likely to be enrolled the listening skills self-study course. Work locus of control was significantly related to group membership $(\underline{r}=$ $.33, \underline{\mathrm{n}}=242, \underline{\mathrm{p}}<.001)$, other SDL activity (listening skills, time 1$)(\underline{\mathrm{r}}=-.34, \underline{\mathrm{n}}=$ 242, $\mathrm{p}<.001$ ), and other SDL activity (work-related, time 1$)(\underline{r}=-.42, \underline{\mathrm{n}}=242, \mathrm{p}$ $<.001)$ such that more internals enrolled in the listening skills course as well as engaged in a greater amount of other SDL activity to develop their listening skills and other work-related skills. Group membership and other SDL activity (listening skills, time 2) were significantly related to learning (time 3$)(\underline{r}=-.78, \underline{n}=227, \underline{p}<$ $.001 ; \underline{\mathrm{r}}=.14, \underline{\mathrm{n}}=226, \underline{\mathrm{p}}<.05$, respectively). And finally, learning (time 3 ) was related to listening skills performance ratings (time 3$)(\underline{r}=.21, \underline{\mathrm{n}}=218, \underline{\mathrm{p}}<.001)$. While these correlations provide preliminary support for some hypotheses, further analyses were conducted to more rigorously test the hypotheses and explore combined effects. Also, post hoc analyses were performed to examine some alternative explanations for the data. 
Testing the Hypotheses

Antecedents to SDL activity. Hypotheses 1 through 9 posit relationships between three individual traits (SDL readiness, work locus of control, and cognitive ability) and three types of SDL activity (group membership, other SDL activity, and extent engaged in course). SDL readiness scores were higher among the participant group than the control group. Also, the participant group had lower work locus of control scores (i.e., more internal work LOC) than the control group. To test these hypotheses, further multiple regressions were performed.

Hypotheses 1,2, and 3 stated that the three individual traits would be related to group membership. While the zero-order correlations supported that SDL readiness (Hypothesis 1) and work LOC (Hypothesis 2) were related to group membership, the correlation between cognitive ability (Hypothesis 3 ) and group membership only approached significance $(\underline{r}=-.12, \underline{\mathrm{n}}=242, \underline{\mathrm{p}}<.10)$. To further test the antecedents of SDL activity, multiple regressions were performed to examine their combined effects on the dependent variables. First, group membership (i.e., enrollment in the listening skills course) was regressed on SDL readiness, work LOC, and cognitive ability and a significant result was found $(\mathrm{F}(3$, $238)=17.327, \mathrm{p}<.001)$. With all three predictors entered into the equation, SDL readiness $(\beta=-.25, \mathrm{p}<.001)$ and work locus of control $(\beta=.31, \mathrm{p}<.001)$ remain significant predictors of group membership, while cognitive ability does not $(\beta=$ - 
$.05, \mathrm{p}>.05)$. Specifically, more individuals that had a greater preference for SDL and greater internality were enrolled in the listening skills self-study course. Cognitive ability did not predict participation in the targeted SDL course.

Hypotheses 4, 5, and 6 proposed relationships between the three individual traits and other SDL activity outside of the targeted listening skills course. The zero-order correlations provided preliminary support for Hypothesis 5, showing a significant relationship between work LOC and other SDL activity to develop listening skills and other work-related skills. Correlations between SDL readiness and other SDL (Hypothesis 4) and cognitive ability and other SDL activity (Hypothesis 6) were all non-significant. To examine the potential combined effects of these antecedents on other SDL activity, three multiple regressions were performed regressing each type of other SDL activity (listening skills, other workrelated skills, and personal interests) on SDL readiness, work LOC, and cognitive ability. For other SDL activity (listening skills, time 1), a significant result was found $(\mathrm{F}(3,238)=10.48, \mathrm{p}<.001)$ with only work locus of control emerging as a significant predictor $(\beta=-.34, \mathrm{p}<.001)$. For other SDL activity (work-related skills, time 1), again, a significant result was found $(\mathrm{F}(3,238)=17.04, \mathrm{p}<.001)$ with work locus of control emerging as a significant predictor $(\beta=-.42, \mathrm{p}<.001)$. For other SDL activity (personal interests, time 1), no significant result was found $(\mathrm{F}(3,238)=0.48, \mathrm{p}>.05)$. 
Finally, the next three hypotheses posit that SDL readiness (Hypothesis 7), work LOC (Hypothesis 8), and cognitive ability (Hypothesis 9) would be related to the extent to which participants engaged in the listening skills course. Extent engaged in course (participant group only) was regressed on SDL readiness, work LOC, and cognitive ability. The result was nonsignificant $(\mathrm{F}(3,110)=0.89, \mathrm{p}>$ $.05)$ SDL readiness and work LOC did not predict SDL activity within the participant group.

Effects of SDL activity on learning. Hypotheses 10,11, and 12 state that group membership in the listening skills course (Hypothesis 10), other SDL activity to develop listening skills between time 1 and time 2 (Hypothesis 11) and greater engagement in the listening skills course (Hypothesis 12) would be related to greater learning. The learning baseline scores were quite similar for both groups (participant mean $=8.45$, control mean $=8.29)^{2}$. However, at time 2, after the participant group had completed the course, the average participant group learning score rose to 14.61 whereas the average control group score was 8.50 , indicating that the participant group acquired more knowledge of listening skills as a result of the SDL course.

\footnotetext{
${ }^{2}$ Possible range of the listening skills baseline and learning measure was $0-20$. No evidence of ceiling effects was found.
} 
Two hierarchical regressions were performed to further examine the effects of SDL activity across both groups and within the participant group. A hierarchical regression was performed to examine the combined effects of group membership and other SDL activity on learning, covarying out the effect of the learning baseline at time 1. In the first step, learning (time 3) was regressed on the learning baseline (time 1). A significant results was found $\left(\mathrm{F}(1,224)=76.41, \mathrm{R}^{2}=.24, \mathrm{p}<.001\right)$ such that higher baseline scores were related to higher learning scores, as would be expected. In step 2, group membership and other SDL activity (listening skills, time 2) were entered into the equation, explaining a significant amount of additional variance $\left(\Delta \underline{\mathrm{F}}(3,222)=304.59, \Delta \mathrm{R}^{2}=.58, \mathrm{p}<.05\right)$. After covarying out the effects of previous listening skills knowledge (learning baseline, time 1), group membership served as a significant predictor of learning $(\beta=-.77, \mathrm{p}<.001)$ such that individuals who engaged in the listening skills course demonstrated greater learning that those in the control group. Other SDL activity (listening skills time 2) aimed at improving listening skills between time 1 and time 2 did not significantly predict learning $(\beta=-.01, \mathrm{p}>.05)$.

A second hierarchical regression was performed to examine how the extent to which participants engaged in the course impacted learning. In the first step, learning (time 3) was regressed on learning baseline (time 1) for the participant group, obtaining a significant results $\left(\mathrm{F}(1,112)=184.41, \mathrm{R}^{2}=.62, \mathrm{p}<.001\right)$. The 
second step added extent engaged in course (participant group) to the equation, accounting for additional significant variance $\left(\Delta \underline{\mathrm{F}}(3,111)=-87.41, \Delta \mathrm{R}^{2}=.01, \mathrm{p}<\right.$ $.05)$. The extent to which participants engaged in the course served as a significant predictor of learning $(\beta=-.12, p<.05)$.

Effects of learning on performance. Hypotheses 13, 14, and 15 posit relationships between learning and changes in performance. In particular, greater learning will result in greater changes in performance (Hypothesis 13), even within the participant group (Hypothesis 14) with a stronger relationship shown between learning and listening skills performance improvements than between learning and overall performance improvement (Hypothesis 15). For overall performance, at time 1, individuals in the participant and control groups received performance ratings that were almost identical (participant mean $=3.32$, control mean $=3.30$ ). At time 3, these scores changed very little (participant mean $=3.34$, control mean $=$ 3.32). For listening skills performance, at time 1 , average ratings for individuals in the control group (mean $=2.96$ ) were significantly higher than average ratings for individuals in the participant group (mean $=2.69$ ). Thus, individuals with weaker listening skills performance ratings enrolled in the course. After the course, at time 3, listening skills performance ratings rose somewhat for the participant group (mean $=3.09)$ but remained essentially unchanged for the control group (mean $=$ 
2.97). These results suggest the listening skills course did impact listening skills performance. $^{3}$

Hierarchical regressions were performed to further examine the effects of learning (time 3) on performance (time 3). For these analyses, performance was regressed on learning baseline (time 1) and performance (time 1) in step 1 to covary out these effects. Then learning (time 3) was entered into the equation. These analyses were performed separately for overall performance and listening skills performance.

For overall performance, step 1 (overall performance (time 3) regressed on learning baseline (time 1) and overall performance (time 1)) was significant $(\underline{F}(2$, $\left.215)=910.72, \mathrm{R}^{2}=.98, \mathrm{p}<.001\right)$. However, when learning (time 3 ) was entered in step 2, the additional variance explained was not significant $(\Delta \underline{\mathrm{F}}(3,214)=9.66$, $\Delta \mathrm{R}^{2}=.00, \mathrm{p}>.05$ ). In other words, learning was not associated with higher levels of overall performance.

For listening skills performance, step 1 was significant $(\underline{F}(2,215)=485.46$, $\left.\mathrm{R}^{2}=.82, \mathrm{p}<.001\right)$. When learning was entered at step 2 , a significant amount of

\footnotetext{
${ }^{3}$ Possible range of performance ratings was $1-5$. No evidence of ceiling effects was found. Average ratings indicate slightly above average overall performance and average to slightly below average listening skill performance.
} 
additional variance was explained $\left(\Delta \underline{F}(3,214)=50.40, \Delta R^{2}=.04, p<.05\right)$. As hypothesized, learning $(\beta=-.24, \mathrm{p}<.001)$ was associated with higher levels of listening skills performance. These results provide support for Hypothesis 15 and partial support for Hypothesis 13.

To examine the effects of learning on performance among those enrolled in the listening skills course only, these same sets of analyses were performed on only the participant group. Learning did not significantly predict overall performance or listening skill performance, providing no support for Hypothesis 14.

\section{$\underline{\text { Post-Hoc Analyses }}$}

A number of post hoc analyses were performed to explore the findings more fully. First, the role of SDL in mediating the relationship between SDL readiness and performance was explored. Second, most people would agree that listening skills are important for a managerial position; however, the degree of importance, especially as indicated by one's supervisor, may vary. Analyses were performed to explore the effects of job skill importance on SDL activity. Third, the amount and type of SDL activity was explored to contribute new information on work-based SDL activity to the SDL literature. And fourth, cognitive ability was not found to be a significant predictor of SDL activity. Alternative explanations regarding the role of cognitive ability in the SDL process were explored. 
Mediating relationships. Previous researchers have found a significant relationship between SDL readiness and overall performance. Findings from the current study do not support this finding. SDL readiness was not related to either overall performance (time 3$)(\mathrm{r}=.05, \underline{\mathrm{n}}=229, \mathrm{p}>.05)$ or listening skills performance (time 3) $(\underline{r}=-.03, \underline{n}=229, \underline{p}>.05)$. However, to better test this relationship, a hierarchical regression was performed to test the mediating role of learning between SDL readiness and performance, covarying out time 1 effects. Because Work Locus of Control (WLOC) emerged as a significant antecedent as well as SDL readiness, WLOC was included in these post-hoc analyses. These analyses allow for a further exploration of direct and indirect effects on listening skill performance.

In the first step, listening skills performance (time 1) and learning baseline (time 1) were entered to covary out time 1 effects $\left(\underline{F}(2,215)=485.46, R^{2}=.82, p\right.$ $<.001$ ). SDL readiness and Work Locus of control was entered at step 2, accounting for a significant amount of additional variance $(\Delta \underline{F}(4,213)=21.50$, $\left.\Delta \mathrm{R}^{2}=.01, \mathrm{p}<.05\right)$. Both SDL readiness $(\beta=.06, \mathrm{p}<.05)$ and Work Locus of Control $(\beta=-.07, \underline{p}<.05)$ significantly predicted listening skills performance. Individuals with higher SDL readiness scores and individuals with more internal WLOC showed greater listening skills performance. In step 3, the proposed mediator learning was entered, explaining a significant amount of additional 
variance $\left(\Delta \underline{\mathrm{F}}(5,212)=26.73, \Delta \mathrm{R}^{2}=.03, \mathrm{p}<.05\right)$. At this step, learning was a significant predictor of performance $(\beta=.23, \mathrm{p}<.001)$ and SDL readiness and work locus of control were no longer significant predictors of performance $(\beta=.02$, $\mathrm{p}>.05 ; \beta=-.02, \mathrm{p}>.05$, respectively). Thus, learning fits the classic model for mediation.

Importance of listening skills for the job. In addition to performance ratings, supervisors were asked to report on a 1 (not important) to 5 (critical) scale: "How important are listening skills for this employee's job?" Job skill importance would likely play a critical role in deciding to focus SDL activity on developing that particular job skill (listening skills in this case). Correlations show some support for this premise: importance ratings were significantly related to group membership $(\underline{r}=-.14, \underline{\mathrm{n}}=226, \mathrm{p}<.05)$. The relationships between job skill importance and other antecedents to SDL activity were explored further using multiple regression. Group membership was regressed on to the significant antecedents identified in hypotheses testing - SDL readiness and WLOC - as well as job skill importance. The overall equation was significant $(\mathrm{F}(3,225)=16.79, \mathrm{p}$ $<.001)$ with SDL readiness $(\beta=-.25, \mathrm{p}<.001)$ and work $\operatorname{LOC}(\beta=.30, \mathrm{p}<.001)$ emerging as significant predictors and job skill importance approaching significance $(\beta=-.10, \mathrm{p}<.10)$. These results provide evidence that job skill 
importance, at least through the eyes of one's supervisor, may influence individuals' decisions to engage in SDL.

Other SDL activity: Frequency and use. While the current study did not make any specific hypotheses regarding the frequency and use of different types of SDL activities to develop in work and personal interest areas, data was collected on all respondents in these areas to supplement the existing literature on work-directed SDL activities. Within a sample of 242 respondents, $67.4 \%$ reported engaging in some type of SDL activity some time between the year prior to the beginning of the study through the completion of the current study. Broken down by focus, 35 individuals $(14.5 \%)$ reported engaging in some other SDL activity to develop their listening skills. It is interesting to note that individuals in the participant group were more likely to engage in other SDL activity targeted at listening skills development $($ mean $=.38)$ than individuals in the control group $($ mean $=.18)$ one year prior to the study. One hundred three individuals (42.6\%) reported engaging in SDL activity focused on other work-related skills. Preliminary results show no difference between the participant and control groups in other SDL activity. And 76 individuals (31.4\%) reported engaging in SDL activity to fulfill a personal interest or hobby. Individuals in the participant group reported engaging in more SDL activities targeted at developing in areas of personal interests (mean $=.80$ ) than individuals in the control group (mean $=.34$ ). Broken down by activity type across 
all areas of skill development (listening skills, other work-related skills, and personal interests), books were the most commonly used SDL activity (18.9\% reported using books), followed by CD-ROMs (17.0\%), other internet resources (14.7\%), audiotapes (13.1\%), classroom-based courses (13.0\%), on-the-job activities (10.0\%), help from others $(9.5 \%)$, online courses $(7.6 \%)$, videos, workshops (7.2\%), help from a mentor (5.4\%), other unspecified activities (5.0\%), seminars (4.5\%), LISTSERVs (3.1\%), conferences (1.8\%), and correspondence courses $(0.9 \%)$.

Broken down by type of SDL activity for each point of focus, the following patterns were seen. For listening skills, the most commonly used SDL activity were books ( $4.4 \%$ of the total sample reported using books to develop their listening skills), followed by help from others (2.7\%), on-the-job activities, audio tapes, other internet resources $(2.2 \%), \mathrm{CD}-\mathrm{ROM}$, classroom-based learning, workshops $(1.8 \%)$, help from a mentor $(1.3 \%)$, videos, other unspecified activities $(0.9 \%)$, online courses, and seminars $(0.4 \%)$. No one reported using conferences, correspondence courses, or LISTSERVs to improve their listening skills. For other work-related skills, books and CD-ROMs were the most commonly used SDL activity $(9.3 \%)$, followed by on-the-job activities, classroom-based courses $(8.0 \%)$, audio tapes (7.6\%), other internet resources (7.5\%), help from others, online courses $(5.8 \%)$, workshops $(4.9 \%)$, help from a mentor $(4.0 \%)$, videos $(3.6 \%)$, 
seminars (2.7\%), LISTSERVs (1.8\%), and conferences (1.3\%). No one reported using correspondence courses or other activities to improve other work-related skills. For personal interests and hobbies, CD-ROMs were the most frequently used SDL activity (6.7\%), followed by books (6.2\%), other internet resources (5.8\%), other unspecified activities (4.9\%), classroom-based courses (4.0\%), audiotapes, workshops (3.6\%), help from others $(2.2 \%)$, online courses $(1.8 \%)$, seminars, workshops, LISTSERVs (1.3\%), correspondence courses $(0.9 \%)$, and conferences $(0.4 \%)$. No one reported using the help of a mentor or on-the-job activities to learn in areas of personal interest. While these percentages may seem small, it reflects the breakdown by focus reported previously. For example, only $14.5 \%$ of the sample engaged in listening skills. Split across 16 types of SDL activities, the percentage of individuals that engage in any one of these activities will be smaller.

Differences in the types of SDL activity used by individuals in the participant group versus the control group emerged as well. In particular, individuals in the participant group (i.e., individuals enrolled in the online listening skills course) reported using CD-ROMs $(\underline{F}(1,222)=5.57, \mathrm{p}<.05)$, on-line courses $(\underline{F}(1,221)=6.58, \mathrm{p}<.05)$, and other internet resources $(\underline{F}(1,222)=5.49, \underline{p}<.05)$ to a greater extent than individuals in the control group. No activities emerged as 
more common among individuals in the control group than individuals in the participants group.

Role of cognitive ability in SDL. Cognitive ability received no support as a predictor of SDL activity, contrary to expectations. Perhaps cognitive ability served a different role in the process. Specifically, when studying difference in learning, a key variable to consider would be an individuals' capacity for learning (i.e., cognitive ability). The correlations suggest cognitive ability was positively related to learning (time 3$)(\underline{r}=.53, \underline{n}=227, \underline{p}<.001)$. Multiple regressions were performed to examine the impact of cognitive ability along side the other learning predictors - SDL activity.

First, the effect of cognitive ability on learning across both groups was explored in combination with other predictors of learning. In the first step, learning (time 3) was regressed on the learning baseline (time 1) to covary out the effect of prior knowledge. As identified in earlier analyses, this step was significant $(\underline{F}(1$, $224)=76.41, \mathrm{R}^{2}=.25, \mathrm{p}<.001$ ). Group membership, other SDL activity (listening skills, time 2), and cognitive ability were entered in step 2 . This step explained a significant amount of additional variance $\left(\Delta \underline{\mathrm{F}}(4,221)=245.92, \Delta \mathrm{R}^{2}=.60, \mathrm{p}<\right.$ .001) serving as significant predictors of learning.

Next, the effect of cognitive ability on learning for the participant group only was explored in combination with other predictors of learning. The first step, 
in which learning (time 3) was regressed on learning baseline (time 1), was significant $\left(\underline{F}(1,112)=184.41, R^{2}=.62, p<.001\right)$. In step 2, extent engaged in course and cognitive ability were entered. This step explained a significant amount of additional variance $\left(\Delta \underline{F}(3,110)=83.76, \Delta R^{2}=.14, p<.001\right)$ with both extent engaged in course $(\beta=.09, \mathrm{p}<.05)$ and cognitive ability $(\beta=.56, \mathrm{p}<.001)$ with group membership $(\beta=-.75, \mathrm{p}<.001)$ and cognitive ability $(\beta=.20, \mathrm{p}<.001)$ serving as significant predictors of learning. The results from these analyses suggest cognitive ability played a role in learning. 


\section{Discussion}

This study bridged together two fields (adult educations and organizational psychology) to study self-directed learning in a work setting. Guglielmino, Guglielmino, and Long (1987) have held that the principles of SDL can be applied to a work context and suggested that a measure of preference for SDL (i.e., SDL readiness) is suitable for selecting high performers. The present study explored these concepts by investigating the process by which SDL readiness impacts performance. I proposed that SDL readiness, along with work locus of control and cognitive ability, would predict SDL activity. SDL activity would then heighten learning, which in turn, would improve performance.

Results supported many of the proposed relationships. In particular, SDL readiness and work locus of control predicted membership in the target SDL course and the extent to which participants engaged in the course. Participation in the listening skills course and the extent to which they engaged in the course predicted greater learning, which in turn predicted improved listening skills performance three months after the completion of the course.

The results are discussed in greater detail below. I address the implications for the present findings, the relationships between present and past theory and research, and possible explanations for unsupported hypotheses. Then I discuss limitations of the current study and identify future directions for research. 
Antecedents of SDL Activity

Previous research on SDL in the workplace has focused on SDL characteristics of the individual (i.e., SDL readiness) and its relationship to performance not SDL activity. SDL readiness was combined with two variables (work locus of control and cognitive ability) commonly used in organizational research to predict SDL activity. SDL activity was defined in three ways to capture a rich composition of this construct: participation in the targeted listening skills course (dichotomous), the extent to which course participants utilized course features, and the extent to which respondents engaged in other SDL activity to develop their listening skills, other work-related skills, and personal interests or hobbies.

The results supported the hypotheses that SDL readiness and work locus of control predicted participation in the listening skills course. Those with a stronger preference for SDL and an internal work locus of control were more likely to enroll in the listening skills course than those with less of a preference for SDL and an external work locus of control. Internal work locus of control also predicted greater engagement in other SDL activities to develop individuals' listening skills and other work-related skills. These results support the premise that individuals with a stronger preference for SDL activities are more likely to engage in SDL than individuals with a weaker preference for SDL. In addition, these results also 
support Katz and Kahn (1978), Spector (1982), and Blau (1993)'s theory and research finding that internals (LOC) are more apt to engage in initiative-based activitics such as self training.

Hypotheses regarding cognitive ability as a predictor of SDL activity were not supported. The role of cognitive ability in the theoretical model may have been placed. Post-hoc analyses suggested that cognitive ability predicted learning. That is, people with higher cognitive ability scores learned more. This finding, while not hypothesized, is not surprising. Cognitive ability is often used as a measure of aptitude for learning.

The extent to which participants engaged in the listening skills course (i.e., utilized its various features) was not significantly related to any of the proposed antecedents. Thus, studied as a group, differences among individuals enrolled in the course on SDL readiness and locus of control did not differentiate activity within a particular SDL experience. It is possible that those measures were not sensitive enough to detect differences among self-directed individuals' actions. Another possibility is insufficient sample size, and thus, insufficient power to detect these differences. More research is needed to examine this issue.

Finally, although SDL readiness predicted participation in the on-line listening skills course, it did not predict engagement in other forms of SDL activity to develop individuals' listening skills, other work-related skills, or personal 
interests or hobbies. This finding was surprising. One possible explanation is the measurement of other SDL activity. Past research by Tough (1971) and Penland (1977) have shown approximately 80 to $90 \%$ of adults engage in some form of SDL activity. The present study found similar results with approximately $67 \%$ of the respondents engaging in some form of SDL activity. However, the measure used asked respondents to self-report the extent to which they engaged in each of 16 activities. Extent was defined as: to no extent, to a little extent, to some extent, to a great extent, and to a very great extent. However, these anchors were not defined. Respondents looking at the scale may have interpreted this differently. For example, which response is most appropriate if an individual read one book in the last year? A more quantifiable measure of SDL activity that was more objective and less subjective may have found different results.

Beyond the proposed relationships, certain demographic variables were also associated with SDL activity, in particular, participation in the on-line listening skills course. Specifically, individuals who were male, worked fewer hours per week, and had fewer children were more likely to engage in the listening skills course than individuals who were female, worked more hours, and had more children. This finding suggests that individuals with more time are more likely to take on SDL activities. 
Effects of SDL Activity on Learning

While the use of SDL activities as a means of self-training has been readily utilized by organizations, few studies exist that demonstrate their effectiveness on facilitating learning (or subsequent performance). The current study examined the impact of a listening skills SDL activity focused on developing listening skills on learning. Of the three SDL activity measures proposed to predict learning, participation in the listening skills course and the extent to which individuals engaged in the listening skills course predicted learning. That is, individuals who participated in the listening skills course learned more than individuals who did not enroll in the course. Of those that participated in the course, those that utilized the features of the course more fully learned more than participants who used the course in a more limited capacity. These findings support the premise that SDL activities, at least as found in this course, are an effective means for employees to gain knowledge on a specific topic.

The hypothesis that other SDL activity aimed at developing listening skills between time 1 and time 2 would predict learning was not supported. As discussed earlier, the variability of this measure was extremely limited. The time period between time 1 and time 2 was relatively short (approximately 2 to 4 months). With insufficient variability, it is unlikely that this measure could have predicted differences in learning. Perhaps the time period was too short to adequately 
measure other SDL activities. Alternatively, the measurement problems of other SDL activity discussed above may also have contributed to the lack of support for this hypothesis.

\section{Impact of Learning on Performance}

The effects of learning on overall and listening skills performance obtained mixed results. Overall performance was not significantly different between the participant and the control groups and did not change as a result of the listening skills course. However, listening skills performance showed different results. At time 1 , individuals in the participant group received lower listening skills performance ratings than individuals in the control group. At time 3, 3 months after the SDL course had been completed, individuals in the participant group received higher ratings (than at time 1), whereas ratings for the control group remained essentially unchanged. When examining the effects of learning on performance across both groups, learning significantly predicted improved listening skill performance three months later. Simply put, individuals who acquired more knowledge on listening skills were rated more highly on listening skills performance. This would suggest that learning was transferred back to the job to improve performance.

However, when looking at the participants group only, greater learning did not predict improvements in listening skills performance, contrary to expectations. 
One possible explanation is reduced power due to the reduction in sample size. An alternative explanation could be a lack of sensitivity of the measures. For example, perhaps a richer learning measure that asked more detailed questions form the course was nceded. More research is needed to explore the effects of learning through SDL activity on performance.

Finally, the relationship between learning and overall job performance was not significant. Although this finding did not support the hypothesized relationship between these two variables, it did lend support to the proposed hypothesis that the relationship between learning and listening skills performance (which was significant) would be stronger than the relationship between learning and overall performance. Learning was measured specifically to capture listening skills knowledge. If listening skills doesn't comprise a large enough portion of a manager's overall performance rating, then changes in listening skills would not be strong enough to affect the overall performance rating. Looking at the overall performance rating items, one can see where better listening skills may influence the ratings, but not in a strong, direct manner.

$\underline{\text { SDL as a Mediator of the SDL Readiness-Performance Relationship }}$

As described earlier, several researchers (Guglielmino, Guglielmino, and Long. 1987; Roberts, 1986; Abbott and Dahmus, 1990) found a positive relationship between SDL readiness and overall job performance. The present 
study did not find a significant relationship between SDL readiness and overall performance. However, given the moderate correlation between SDL readiness and listening skills performance (time 1) and significant effects found between learning and listening skills performance, post-hoc analyses were performed to determine if SDL did in fact mediate the SDL readiness-performance relationship. A significant result found that SDL readiness and work locus of control significantly predicted listening skill performance. However, when learning was entered into the equation, it served as a mediator: learning significantly predicted listening skills performance and the relationship between SDL readiness and work locus with listening skills performance became nonsignificant.

These findings support the assertion that the relationship between SDL readiness and performance is explained through the effects of self-directed learning. The present researcher would caution others from using SDL readiness as a selection tool, but instead to use this construct and measure to promote self-directed activities in the workplace.

Importance of Job Skill on SDL Activity

Post-hoc analyses also revealed some interesting results related to the importance of a particular skill for one's job. The findings tentatively showed that individuals who participated in the listening skills course had supervisors who viewed listening skills as more important for the job. These results should 
interpreted with caution, for the relationship only approached statistical significance and it was not part of the originally conceived model. However, it does merit further attention, examining not only supervisor's perceptions but the employec's as well.

Frequency and use of SDL Activities

Consistent with SDL theory, the results showed that individuals used a variety of SDL activities such as books, computers, and other people to develop their listening skills, other work-related skills, and personal interests or hobbies. Differences among the participant and control groups revealed an interesting pattern. Specifically, individuals enrolled in the on-line listening skills course were more likely to use CD-ROMs, on-line courses, and other internet resources than individuals in the control group. This finding suggests individuals have preferences for different types of SDL activities, in this case computer-based activities. Similarly, individuals enrolled in the listening skills course reported more other SDL activities in the areas of listening skills and to develop personal interests or hobbies. Future research should continue to explore these patterns as a means of studying such issues as the impact of preferences on motivation, aptitude, and outcomes. 


\section{Limitations of Study}

Some limitations with the study's design and measurement of certain variables should be considered when interpreting the results of the study. First, the focus here was only on one self-study course in one organization. This design was chosen to control for a number of other factors (e.g., making comparisons across courses, types of activities, organizations, etc.) which allowed for the proposed model to be studied with greater confidence. However, generalizing these findings to other types of SDL activity is tentative at best. More support for this model should be sough through additional research to verify these relationships in other courses and organizations.

Second, some of the measures could be refined. The SDL readiness measure significantly predicted a number of behaviors, however, the measure did not exhibit the underlying factor structure that has been found in previous research. Could this be the result of using the measure in a work setting? Brookfield (1984) called for more research on working adults, however, in doing so, the underlying scale characteristics should be examined for this population. If a consistent factor structure is found, then the use of subscales should be examined.

Also, the soundness of the other SDL activity measure should be explored. The 16 items chosen represented an assortment of SDL activities; however, there may be other activities to identify or different ways to cluster activities together. In 
addition, the rating scale could be modified or defined with greater specificity so respondents can clcarly report their activities, as discussed earlier. Finally, another possibility would be to obtain objective measures of SDL activity (e.g., previous course enrollment).

The measurement of listening skills performance may also be improved upon by gathering ratings from those individuals who observe it these behaviors the most. Listening skills, by its nature, is something that everyone witnesses when interacting with others. One's boss may be someone too removed from the individual's daily work to observe changes in listening skills. Listening skill performance may lend itself well to 360-degree measurement, capturing the impressions of those who interact with that individual the most.

Finally, the measurement of listening skills may have been biased because supervisors were most likely aware of their direct reports' participation in the online courses. Therefore, while we cannot be sure the manner in which knowledge of participation may have influenced ratings, supervisors may have rated listening skills performance higher for those enrolled in the course simply because they knew their employees were working on that skill or it may have biased their perception of performance. Had a third group been available that enrolled in the course but had not yet taken the course, this effect could have been studied. However, since this 
group was unavailable, these alternative explanations cannot be ruled out and, therefore, the results should be interpreted with caution.

Future directions for research

The present study proposed and found modest support for a model that explained the process through which SDL readiness affects performance. It also demonstrated the effectiveness of a SDL program on learning and subsequent performance. That said, there is still a long way to go. As mentioned earlier, SDL research in organizational settings is still in its infancy. Thus, there are a number of directions for future research as identified below.

To substantiate and verify the findings of the current study, more research is needed that studies the effectiveness of other types of SDL programs on learning and performance across numerous organizations and industries. The types of programs studied should be varied, for example, leaderless groups, mentoring programs, audio tapes, etc. In addition, researchers should identify other variables from adult education and organizational psychology to study with the variables identified here. For example, other antecedents of SDL activity are plausible such as personal initiative, motivation, and past learning experiences (both successful and unsuccessful). Finally, the importance of demographic variables in relation to the other antecedents of SDL activities should be examined. For example, the findings of the present study suggested that individuals who worked fewer hours 
and have fewer children were more likely to engage in the listening skills course. One interpretation is that individuals with more time are more likely to engage in SDL activity. The relationship between time availability, SDL readiness, and work locus of control and other antecedents should be studied to examine how these variables interact. For example, if individuals had more time, which ones would choose to engage in SDL activity and successfully acquire new knowledge and skills to improve job performance in some way? Examining these types of relationships would cnable us to gain a broader understanding of participation in SDL activity.

Future studies should also explore better ways to measure some of the issues studied herc. For example, the impact of different types of SDL activity on learning, especially in relation to one another is important. Are certain types of SDL programs more effective at improving knowledge, skills, abilities, and performance? Do individuals' preferences for different types of activities influence their learning? Another measure that needs improvement, but a worthy construct to study, is importance of the skill to be learned for successful job performance. The present study examined supervisors' perceptions of importance for job. Future research should also consider the perceptions of the individual actively engaged in the self-directed activity. One measurement issue the present researcher encourages others to follow is the consideration of performance specific to the targeted skill 
domain. Had this study followed past research and studied only overall performance, some important lindings would have been missed. Measuring performance at the appropriate level of specificity is important.

A different path for fiture research is to focus on the self-directed learners. The present study focused more around a particular SDL activity than on the individuals themselves. Focusing on individuals' traits, characteristics, motivations and preferences may unveil some important information. For example, is there such a thing as a self-directed learner in general or does it depend on the topic, situation, and context? Are self-directed learners better able to learn and perform as a result of SDL activity? Can individuals with a low preference for SDL be trained to be more self-directed? These are all interesting questions to explore. Parting Thoughts

The present study introduced a number of issues relevant to organizational research that reflects a pressing need in organizations today. More work is needed for researchers to understand these concepts more closely and provide value for organizations faced with a heavy burden to provide sufficient training for their workforce. 


\section{APPENDIX A}

The Self-I)irceled I cearning Readiness Scale/Learning Preference Assessment *This scale is reproduced here for sake of ease and illustration. This measure is the property of (iugliclmino \& Associates. To obtain a copy of this measure, contact them at 734 Marble Way, Boca Raton, FL 33432. (561) 392-0379.

Scale:

1 = Almost never true of me; I hardly ever feel this way.

$2=$ Not often true of me; I feel this way less than half the time.

$3=$ Sometimes true of me; I feel this way about half the time.

$4=$ Usually true of me; 1 feel this way more than half the time.

$5=$ Almost always truc of me; there are very few times when I don't feel this way.

Items:

1. I'm looking forward to learning as long as I'm living.

2. I know what I want to learn.

3. When I sec something that I don't understand, I stay away from it. (R)

4. If there is something I want to learn, I can figure out a way to learn it.

5. I love to learn.

6. It takes me a while to get started on new projects. (R) 
7. In a classroom, I expect the teacher to tell all class members exactly what to do at all times. ( $R$ )

8. I believe that thinking about who you are, where you are, and where you are going should be a maijor part of every person's education.

9. I don't work very well on my own. (R)

10. If I discover a need for information that I don't have, I know where to go to get it.

11. I can learn things on my own better than most people.

12. Even if I have a great idea, I can't seem to develop a plan for making it work. (R)

13. In a learning experience, I prefer to take part in deciding what will be learned and how.

14. Difficult study doesn't bother me if I'm interested in something.

15. No one but me is truly responsible for what I learn.

16. I can tell whether l'm learning something well or not.

17. There are so many things I want to learn that I wish that there were more hours in a day.

18. If there is something I have decided to learn, I can find time for it, no matter how busy I am.

19. Understanding what I read is a problem for me. (R) 
20. If I don't learn, it's not my fault. (R)

21. I know when I need to learn more about something.

22. If I can understand something well enough to get a good grade on a test, it doesn't bother me if I still have questions about it. (R)

23. I think libraries are boring places. (R)

24. The people I admire most are always learning new things.

25. I can think of many different ways to learn about a new topic.

26. I try to relate what I am learning to my long-term goals.

27. I am capable of learning for myself almost anything I might need to know.

28. I really enjoy tracking down the answer to a question.

29. I don't like dealing with questions where there is not one right answer. (R)

30. I have a lot of curiosity about things.

31. I'll be glad when I'm finished learning. (R)

32. I'm not as interested in learning as some other people seem to be. (R)

33. I don't have any problem with basic study skills.

34. I like to try new things, even if I'm not sure how they will turn out.

35. I don't like it when people who really know what they're doing point out mistakes that I am making. (R)

36. I'm good at thinking of unusual ways to do things.

37. I like to think about the future. 
38. I'm better than most people are at trying to find out the things I need to know.

39. I think of problems as challenges, not stopsigns.

40. I can make myself do what I think I should.

41. I'm happy with the way $l$ investigate problems.

42. I become a leader in group learning situations.

43. I enjoy discussing idcas.

44. I don't like challenging learning situations. (R)

45. I have a strong desire to learn new things.

46. The more I learn, the more exciting the world becomes.

47. Learning is fun.

48. It's better to stick with the learning methods that we know will work instead of always trying new ones. $(R)$

49. I want to learn more so that I can keep growing as a person.

50. I am responsible for my learning -- no one else is.

51. Learning how to learn is important to me.

52. I will never be too old to learn new things.

53. Constant learning is a bore. (R)

54. Learning is a tool for life.

55. I learn several new things on my own each year.

56. Learning doesn't make any difference in my life. (R) 
57. I am an effective learner in the classroom and on my own.

58. Learners are leaders. 


\section{APPENDIX B \\ Work Locus of Control Scale}

Scale: $1=$ disalgrec very much, 2 = disagree moderately, 3 = disagree slightly, $4=$ agree slightly, $5=$ agrec moderately, $6=$ agree very much

\section{Items:}

1. A job is what you make of it. (R)

2. On most jobs, people can pretty much accomplish whatever they set out to accomplish. (R)

3. If you know what you want out of a job, you can find a job that gives it to you. (R)

4. If employces are unhappy with a decision made by their boss, they should do something about it. (R)

5. Getting the job you want is mostly a matter of luck.

6. Making moncy is primarily a matter of good fortune.

7. Most people are capable of doing their jobs well if they make the effort. (R)

8. In order to get a really good job you need to have family members or friends in high places.

9. Promotions are usually a matter of good fortune. 
10. When it comes to landing a really good job, who you know is more important than what you know.

11. Promotions are given to employees who perform well on the job. (R)

12. To make a lot of moncy you have to know the right people.

13. It takes a lot of luck to be an outstanding employee on most jobs.

14. People who perform their jobs well generally get rewarded for it. (R)

15. Most employees have more influence on their supervisors than they think they do. (R)

16. The main difference between people who make a lot of money and people who make a little money is luck. 


\section{APPENDIX C \\ Overall job performance measure}

How much does this employee get done?

(1) Very low work output. Performs only at an unsatisfactory pace.

(2) Low work output. Performs at a slow pace.

(3) Good work output. Performs at an acceptable pace.

(4) High work output. Performs at a fast pace.

(5) Very high work output. Performs at an unusually fast pace.

How good is the quality of work?

(1) Quality of work is unacceptable and hardly ever meets minimum standards.

(2) Quality of work is usually acceptable but somewhat inferior.

(3) Quality of work is acceptable but usually not superior.

(4) Quality of work is usually superior.

(5) Quality of work is almost always the highest.

How accurate is the work?

(1) Makes very many mistakes. Work needs constant checking.

(2) Makes frequent mistakes. Work needs more checking than is desirable.

(3) Makes mistakes at times. Work is acceptable and needs only normal checking.

(4) Makes few mistakes. Work seldom needs checking.

(5) Rarely makes a mistake. Work almost never needs checking.

How much does the employee know about the job?

(1) Has very limited knowledge. Does not know enough to do the job adequately.

(2) Has little knowledge. Knows enough to get by.

(3) Has acceptable amount of knowledge. Knows enough to do good work.

(4) Has very broad knowledge. Knows enough to do very good work.

(5) Has complete knowledge. Knows enough to perform all work extremely well. 
How large a varicly of job duties can the employee perform efficiently?

(1) Cannot perform different operations adequately.

(2) Cin perform a limited number of different operations efficiently.

(3) Can perform several different operations efficiently.

(4) Cin perform many different operations efficiently.

(5) Can perform an unusually large variety of different operations efficiently.

Considering all the factors already rated, and only these factors, how good is this employee?

(1) Performance not acceptable.

(2) Performance acceptable at times.

(3) A good and proficient worker.

(4) Performance frequently exceeds job requirements.

(5) An unusually competent worker. Performance almost always exceeds job requirements. 


\section{APPENDIX D}

\section{Listening skills performance measure}

How would you rate this employee's overall listening skills?

(1) Poor; Well below average

(2) Below average

(3) Average

(4) Above average

(5) Excellent; Well above average

How would you rate this employee's ability to comprehend information presented to him or her (e.g., reports back information accurately to others, executes work consistent with information obtained)?
(1) Poor; Well below average
(2) Below average
(3) Average
(4) Above average
(5) Excellent; Well above average

How well does this employee demonstrate to others that their comments were heard (e.g., summarizes, paraphrases, builds on others comments)?

(1) Poor; Well below average

(2) Below average

(3) Average

(4) Above average

(5) Excellent; Well above average

How well does this employee use nonverbals (e.g., eye contact, nodding, open posture) to communicate active listening?
(1) Poor; Well below average
(2) Below average
(3) Average
(4) Above average
(5) Excellent; Well above average 
How important are listening skills for this employee's job?

(1) Not important

(2) Somewhat important

(3) Important

(4) Very important

(5) Critical 


\section{REFERENCES}

Abbott, J., \& Dahmus, S. (1990). Self-directed learning readiness and data processing personnel. Unpublished study, Florida Atlantic University.

Abbott, J., \& Dahmus, S. (1992). Assessing the appropriateness of selfmanaged learning. Journal of Management Development, 11(1), 50-60.

Allerton, T. D. (1975). Selected characteristics of the learning projects pursued by parish ministers in the Louisville metropolitan area. (Doctoral dissertation, University of Georgia, 1974) Dissertation Abstracts International, 35. 6422A.

ASTD (1997). Benchmarking forum. Information obtained from the ASTD web site.

Baghi, H. (1979). The major learning efforts of participants in adult basic education classes and learning centers (Doctoral dissertation, Iowa State University, 1979).

Bayha, R. A. (1984). Self-directed learning readiness of Northwest Missouri farmers as related to learning resource choice and valuing. (Doctoral dissertation, Kansas State University, 1983). Dissertation Abstracts International, $\underline{45}, 50 \mathrm{~A}$. 
Benson, F. B., Jr. (1975). Learning projects of selected administrators in Tennessee college and universities. (Doctoral dissertation, University of Tennessec, 1974). Disscrtation Abstracts International, 35, 4958A.

Blau, G. (1993). Testing the relationship of locus of control to different performance dimensions. Journal of Occupational and Organizational Psychology, $\underline{66}(2), 125-138$.

Bonham, L. A. (1991). Guglielmino's self-directed learning readiness scale: What docs it measure? Adult Education Quarterly, 41, 92-99.

Brockett, R. G. (1983). Self-directed learning and the hard-to-reach adult. Lifelong learning: The adult years, $6(8), 16-18$.

Brockett, R. G. (1985a). Methodological and substantive issues in the measurement of self-directed learning readiness. Adult Education Quarterly, 36, $15-24$.

Brockett, R. G. (1985b). The relationship between self-directed learning readiness and life satisfaction among older adults. Adult Education Quarterly, 35, 210-219.

Brody, N. (1997). Intelligence, schooling, and society. American Psychologist, 52, 1046-1050. 
Broedling, L. A. (1975). Relationship of internal-external control to work motivation and performance in an expectancy model. Journal of Applied Psychology, 60, 65-70.

Brookficld, S. (1981). Independent adult learning. Studies in Adult Education, 13, 15-27.

Brookfield, S. (1984). Self-directed adult learning: A critical paradigm. Adult Education Quarterly, 35, 59-71.

Brookfield, S. (1985). Self-directed learning: A critical review of research. New Directions for Continuing Education, 25, 5-16.

Caffarella, R. S., \& O’Donnell, J. M. (1987). Self-directed adult learning: A critical paradigm revisited. Adult Education Quarterly, 37, 199-211.

Caffarella, R. S., \& O’Donnell, J. M. (1991). Judging the quality of workrelated, self-directed learning. Adult Education Quarterly, 42, 17-29.

Campbell, J. P. (1991). Invited reaction: The compleat self-learner. Human Resource Development Quarterly, 2, 13-20.

Campbell, D. T., \& Stanley, J. C. (1963). Experimental and quasiexperimental designs for research. Boston, MA: Houghton Mifflin Company. Cappelli, P., Bassi, L., Katz, H., Knoke, D., Osterman, P., \& Useem, M. (1997). Change at work. New York: Oxford University Press. 
Carncvalc, A. P. (1995). Enhancing skills in the new economy. In A.

Howard, (1id.), The changing nature of work. San Francisco: Jossey-Bass.

Cascio, W. F. (1991). Applied psychology in personnel management (4th ed.). Englewood Cliffs, NJ: Prentice Hall.

Cascio, W. F. (1995). Whither Industrial and Organizational psychology in a changing world of work? American Psychologist, 50, 928-939.

Coleman, D. F., Irving, G. P. \& Cooper, C. L. (1999). Another look at the locus of control-organizational commitment relationship: It depends on the form of commitment. Journal of Organizational Behavior, 20, 995-1001.

Conn, A. B. (1998). The changing nature of work: Implications for training interventions. Unpublished manuscript, University of Maryland.

Craiger, J. P. (1997). Technology, organizations and work in the 20th century. The Industrial-Organizational Psychologist, 34, 89-96.

DeJoy, J. K., \& DeJoy, D. M. (Sept. 1987). Self-directed learning: The time is now. Training and Development Journal, 41(9), 64-66.

Delahaye, B. L., \& Smith, H. E. (1995). The validity of the Learning Preference Assessment. Adult Education Quarterly, 45, 159-173.

Dodrill, C. B. (1981). An economical method for the evaluation of general intelligence in adults. Journal of Consulting and Clinical Psychology, 49(5), 668673. 
Livans, M. (i. (1974). Extensions of a path-goal theory of motivation. Journal of Applicd P'sychology, 59, 172-178.

lair, J. (1975). Teachers as learners: The learning projects of beginning elementary-school tcachers. (Doctoral dissertation, University of Toronto, 1973). Dissertation Abstracts Intcrnational, 35, 5759-5760A.

Feldman, D. C. (1995). Managing part-time and temporary employment relationships: Individual needs and organizational demands. In M. London (Ed.), Employees, carecrs, and job creation. San Francisco: Jossey-Bass.

Ficld, L. (1989). An investigation into the structure, validity, and reliability of Guglielmino's self-directed learning readiness scale. Adult Education Quarterly, 39, 125-139.

Field, L. (1990). Guglielmino's self-directed learning readiness scale: Should it continue to be used? Adult Education Quarterly, 41, 100-103.

Fitzgibbons, K. V. (1990). Adults' self-directed learner characteristics and library literacy. Doctoral dissertation (Department of Education Policy, Planning, and Administration) at University of Maryland at College Park.

Ganster, D. C. \& Fusilier, M. R. (1989). Control in the workplace. In C. L. Cooper \& I. T. Roberson (Eds.), International review of industrial and organizational psychology (pp. 235-280). Chichester, England UK: John Wiley \& Sons. 
GATB Manual (1970).

Gerber, R., Lankshear, C., Larsson, S., \& Svensson, L. (1995). Self-

directed learning in a work context. Education and Training, 37(8), 26-32.

Gibbons, M., Bailey, A., Comeau, P., \& Schmuck, J., Seymour, S., \& Wallace, D. (1980). Toward a theory of self-directed learning: A study of experts without formal training. Journal of Humanistic Psychology, 20(2), 41-56.

Goldstein, I. (1993). Training in organizations: Needs assessment, development and evaluation. (3rd ed.), Monterey, CA: Brooks/Cole Publishing Company.

Guglielmino, L. M. (1977). Development of self-directed learning readiness scale. Unpublished doctoral dissertation, University of Georgia.

Guglielmino, L. M. (1989). Guglielmino responds to Field's investigation. Adult Education Quarterly, 39, 235-245.

Guglielmino, P. J., \& Guglielmino, L. M. (1991). The learning preference assessment. USA: Organization Design and Development.

Guglielmino, P. J., Guglielmino, L. M., \& Long, H. B. (1987). Selfdirected learning readiness and performance in the workplace. Higher Education, $\underline{16}, 303-317$.

Hall, D. T., \& Mirvis, P. H. (1995). Careers as lifelong learning. In A. Howard, (Ed.), The changing nature of work. San Francisco: Jossey-Bass. 
Hassan, $\Lambda$. M. (1982). An investigation of the learning projects among adults of high and low rcadiness for self-direction in learning. Dissertation Abstracts International, 42, 3838A-3839A.

Hatcher, T. G. (February 1997). The ins and outs of self-directed learning. Training and Development Journal, 51(2), 34-39.

Hawkins, K. A., Faraone, S. V., Pepple, J. R., \& Seidman, L. J. (1990). WAIS-R validation of the Wonderlic Personnel Test as a brief intelligence measure in a psychiatric sample. Psychological Assessment, 2, 198-201.

Hiemstra, R. (1976). The older adult's learning projects. Educational Gerontology, 1, 331-341.

Houle, C. O. (1961). The inquiring mind: A study of the adult who continues to learn. Madison, Wisconsin: University of Wisconsin Press.

Howard, A. (1995). A framework for work change. In A. Howard, (Ed.), The changing nature of work. San Francisco: Jossey-Bass.

Howell, J. M. \& Avolio, B. J. (1993). Transformational leadership, transactional leadership, locus of control, and support for innovation: Key predictors of consolidated-business-unit-performance. Journal of Applied Psychology, 78, 891-902. 
Hunter, J. E. (1989). The Wonderlic Personnel Test as a predictor of training success and job performance. East Lansing, Michigan: Michigan State University, Department of Psychology.

Hunter, J. E. \& Hunter, R. F. (1984). Validity and utility of alternative predictors of job performance. Psychological Bulletin, 96, 72-98.

Johns, W. E. (1974). Selected characteristics of the learning projects pursued by practicing pharmacists. (Doctoral dissertation, University of Georgia, 1973). Dissertation Abstracts International, 34, 4677A.

Johnson, V., Levine, H., \& Rosenthal, E. L. (1977). Learning projects of unemployed adults in New Jersey. New Brunswick, NJ: Educational Advancement Project, Rutgers Labor Education Center.

Kathrein, M. A. (1981). A study of self-directed continued professional learning of members of the Illinois Nurses' Association: Content and process (Doctoral dissertation, Northern Illinois University, 1981). Dissertation Abstracts International, 42, 1902A.

Katz, D. (1964). The motivational basis of organizational behavior. Behavioral Science, 9, 131-146.

Katz, D. \& Kahn, R. (1978). The social psychology of organizations. New York: Wiley. 
Kalufman, II. (i. (1995). Salvaging displaced employees: Job obsolescence, retraining, and redeployment. In M. London (Ed.), Employees, careers, and job creation. San lirancisco: Josscy-Bass.

Kelley, N. L. (1976). A comparative study of professionally related learning projects of secondary school teachers. Unpublished master's thesis, Cornell University.

Kimmons, G. \& Greenhaus, J. H. (1976). Relationship between locus of control and reactions of employees to work characteristics. Psychological Reports, $\underline{39,815-820 .}$

Kinicki, A. J. \& Vecchio, R. P. (1994). Influences on the quality of supervisor-subordinate relations: The role of time-pressure, organizational commitment, and locus of control. Journal of Organizational Behavior, 15, 75-82.

Knowles, M. S. (1975). Self-directed learning: A guide for learners and teachers. New York: Association Press.

Kraiger, K., Ford, J. K., \& Salas, E. (1993). Application of cognitive, skillbased and affective theories of learning outcomes to new methods of training evaluation. Journal of Applied Psychology, 78, 311-328.

Lawler, E. E., III (1993). Creating the high-involvement organization. In Galbraith, J. R., \& Lawler, E. E., III (Eds.), Organizing for the future: The new logic for managing complex organizations. San Francisco: Jossey-Bass. 
LeBlanc, P. J. (1994). The politics of literacy and technology in secondary school classrooms. In C. L. Selfe \& S. Hilligoss (Eds.), Literacy and computers: The complications of technology and learning with technology. New York: Modern Language Association of America.

Lefcourt, H. M. \& Wine, J. (1969). Internal versus external locus of control and the deployment of attention in experimental situations. Canadian Journal of Behavioural Science, 1, 167-181.

Lied, T. R. \& Prichard, R. D. (1976). Relationships between personality variables and components of the expectancy-valence model. Journal of Applied Psychology, 61, 463-467.

Long, H. B. (1989). Some additional criticisms of Field's investigation. Adult Education Quarterly, 39, 240-243.

Macan, T. H., Trusty, M. L. \& Trimble, S. K. (1996). Spector's Work Locus of Control Scale: Dimensionality and validity evidence. Educational and Psychological Measurement, 56, 349-357.

Martocchio, J. J. \& Judge, T. A. (1997). Relationship between conscientiousness and learning in employee training mediating influences of selfdeception and self-efficacy. Journal of Applied Psychology, 82, 764-773. 
Mc(ally, (. (1976). Patterns of learning projects among physical and health education teachers. Reporting Classroom Research (Ontario Educational Rescarch (ouncil), 5(2), 7-8.

McC'une, S. K. (1989). A statistical critique of Field's investigation. As Education Quarterly, 39, 243-245.

Neuman, G. A. \& Wright, J. (1999). Team effectiveness: Beyond skills and cognitive ability. Journal of Applied Psychology, 84, 376-389.

Nystrom, P. C. (1983). Managers' salaries and their beliefs about reinforcement control. Journal of Social Psychology, 122, 291-292.

Oddi, L. (1984). Development of an instrument to measure self-directed continuing learning. Unpublished doctoral dissertation. Northern Illinois University.

Oddi, L. S. (1987). Perspectives on self-directed learning. Adult Educa1 Quarterly, 38, 21-31.

Olson, P. C. (1987). Who computes? In D. W. Livingstone (Ed.), Criti Pedagogy and Cultural Power. South Hadley: Bergin.

Pearlman, K., Schmidt, F. L., \& Hunter, J. E. (1980). Validity generalization results for tests used to predict job proficiency and training succe in clerical employees. Journal of Applied Psychology, 65, 373-406. 
Penland, P. (1977). Self-planned learning in America. Pittsburgh: University of Pittsburgh.

Penland, P. (1979). Self-initiated learning. Adult Education, 29(3), 170179.

Piskurich, G. (Sept. 1991). Quality through self-directed learning. Training \& Development, 45(9), 45-48.

Ree, M. J., Earles, J. A. \& Teachout, M. S. (1994). Predicting job performance: Not much more than g. Journal of Applied Psychology, 79, 518-524.

Roberts, D. G. (1986). A study of the use of self-directed learning readiness scale as related to selected organizational variables. Doctoral dissertation, George Washington University.

Rotter, J. B. (1966). Generalized expectancies for internal versus external control of reinforcement. Psychological Monographs, 80(1), Whole no. 609.

Sabbaghian, Z. S. (1980). Adult self-directedness and self-concept: An exploration of relationships. (Doctoral Dissertation. Iowa State University, 1979). Dissertation Abstracts International, 40, 3701A.

Savoie, M. M. (1979). Continuing education for nurses: Predictors of success in courses requiring a degree of learner self-direction (Doctoral dissertation, University of Toronto, 1979). Dissertation Abstracts International, 40, 6114A. 
Schmidl, I. I.., Hunter, J. E., \& Caplan, J. (1981). Validity generalization results for two job groups in the petrolcum industry. Journal of Applied Psychology, 66, 261-273.

Shackelford, R. A. (1983). Self-directed learning projects among black adults in Havana, Florida (Doctoral dissertation, The Florida State University, 1983). Disscrtation $\Lambda$ bstracts International, 44, 647A.

Shirk, J. C. (1984). Relevance attributed to urban public libraries by adult learners: A case study and content analysis of 81 interviews (Doctoral dissertation, Texas A \& M University, 1983). Dissertation Abstracts International, 45, 53A.

Spear, G. E., \& Mocker, D. W. (1984). The organizing circumstance: Environmental determinants in self-directed learning. Adult Education Quarterly, $\underline{35,} 1-10$.

Spector, P. E. (1982). Behavior in organizations as a function of employee's locus of control. Psychological Bulletin, 91, 482-497.

Spector, P. E. (1988). Development of the Work Locus of Control Scale. Journal of Occupational Psychology, 61, 335-340.

Sternberg, R. J. (1997). Intelligence and lifelong learning: What's new and how can we use it? American Psychologist, 52, 1134-1139.

Szilagyi, A. D. \& Sims, H. P., Jr. (1975). Locus of control and expectancies across multiple occupational levels. Journal of Applied Psychology, 60, 638-640. 
Tannenbaum, S. I., \& Yukl, G. (1992). Training and development in work organizations. Annual Review of Psychology, 43, 399-441.

T'orrance, L:., \& Mourad, S. (1978b). Self-directed learning readiness skills of gifted students and their relationship to thinking creatively about the future. The Gifted Child Quarterly,22, 180-186.

Tough, A. M. (1971). The adult's learning projects. Toronto: Ontario Institute for Studies in Education.

Tough, A. M. (1978). Major learning efforts: Recent research and future directions. Adult Education, 28, 250-263.

Umoren, A. P. (1977). Learning projects: An exploratory study of adults in a selected socioeconomic group. (Doctoral dissertation, University of Nebraska -Lincoln, 1977).

Wagner, R. K. (1997). Intelligence, training, and employment. American Psychologist, 52, 1059-1069.

West, R., \& Bentley, E., Jr. (1989, February). Structural analysis of the self-directed learning readiness scale: A confirmatory factor analysis using LISREL modeling. Paper presented at the Third North American Symposium on Adult SelfDirected Learning, Oklahoma Research Center for Continuing Professional and Higher Education, University of Oklahoma, Norman. 
Wonderlic. Inc. (1999). User's manual for the Wonderlic Personnel Test.

Libertyville, Il..

Wonderlic, E. F. \& Hovland, C. 1. (1939). The Personnel Test: A

restandardized abridgement of the Otis S-A Test for business and industrial use.

Journal of Applied Psychology, 23(6), 685-702.

Zemke, R. (May 1998). In search of self-directed learners. Training, 60-68. 